\title{
Ezh2 Regulates Adult Hippocampal Neurogenesis and Memory
}

\author{
Juan Zhang, ${ }^{1,2 \star}$ Fen Ji, ${ }^{1 \star}$ Yanli Liu, ${ }^{1}$ Xuepei Lei, ${ }^{1,2}$ Hong Li, ${ }^{1}$ Guangju Ji, ${ }^{3}$ Zengqiang Yuan, ${ }^{3}$ and Jianwei Jiao ${ }^{1}$ \\ ${ }^{1}$ State Key Laboratory of Reproductive Biology, Institute of Zoology, Chinese Academy of Sciences, Beijing 100101, China, ${ }^{2}$ University of Chinese Academy \\ of Sciences, Beijing 100049, China, and ${ }^{3}$ Institute of Biophysics, Chinese Academy of Sciences, Beijing 100101, China
}

Adult neurogenesis is thought to be crucial for preserving cognitive functions, which is tightly controlled by various epigenetic regulators. As the methyltransferase of histone H3K27, the role of Ezh2 in neurogenesis of adult mice and its mechanism of action are largely unknown. Here, we show that Ezh2 is expressed in actively dividing neural stem cells (NSCs)/progenitor cells as well as mature neurons, but not in quiescent NSCs in the subgranular zone. The deletion of Ezh2 in NSCs/progenitor cells results in a reduction in progenitor cell proliferation. Furthermore, we found that Ezh2 regulates progenitor cell proliferation by suppressing Pten expression and promoting the activation of Akt-mTOR. Moreover, the loss of Ezh2 in progenitor cells leads to a decrease in the number of neurons, which was observed by long-term tracing. Strikingly, conditional knockout of Ezh2 ultimately results in impairments in spatial learning and memory, contextual fear memory, and pattern separation. Our findings demonstrate the essential role of Ezh2 in the proliferation of progenitor cells, thus providing insight into the molecular mechanisms of adult neurogenesis in preserving cognitive functions.

Key words: adult neural stem cell; Ezh2; hippocampus; learning and memory; neurogenesis

\section{Introduction}

Adult neurogenesis is a process that includes the proliferation of neural stem/progenitor cells, the differentiation of neurons, and the integration of new neurons into the existing neural circuitry (Zhao et al., 2008). Persistent adult neurogenesis is primarily found in two neurogenic regions: the subgranular zone (SGZ) and the subventricular zone (Alvarez-Buylla and Lim, 2004). In the adult SGZ, neural stem cells (NSCs) proliferate, forming intermediate progenitor cells, which then go through several rounds of division and give rise to neuroblasts (Ma et al., 2010). The frequency of NSC division may have a large impact on the number of new neurons. For example, autonomous physical exercise, such as running, can promote NSC division and enhance the production of new neurons (van Praag et al., 2002; Suh et al., 2007; Lugert et al., 2010). As the basic process of neuron generation, adult neurogenesis plays a pivotal role in preserving cognitive functions throughout life. In fact, impaired neurogenesis in the DG of adult mice may account for defective spatial learning

Received Sept. 26, 2013; revised March 2, 2014; accepted March 2, 2014.

Author contributions: J.Z., F.J., and J.J. designed research; J.Z., Y.L., X.L., and H.L. performed research; J.Z., F.J., G.J., Z.Y., and J.J. analyzed data; J.Z., F.J., and J.J. wrote the paper.

This work was supported by grants from the National Key Basic Research Program of China (2014CB964903 and 2014CB964602), the National Science Foundation of China (31371477 and 31300894), the Hundreds Talent Program, and the Strategic Priority Research Program (XDA01020301). We are grateful to Dangsheng Li for critical comment and discussion, members of the Jiao lab for discussion, Shiwen Li for technical assistance, Lei Zhou for mice behavior technical help, Stuart Orkin for providing Ezh2 $2^{f / f}$ mice, and Amelia Eisch for Nestin-CreERT2 mice.

*J.Z. and F.J. contributed equally to this work.

The authors declare no competing financial interests.

Correspondence should be addressed to Jianwei Jiao, PhD, Principal Investigator, Group of Neural Stem Cell and

Neurogenesis, Institute of Zoology, Chinese Academy of Sciences, 1 Beichen West Road, Chaoyang District, Beijing 100101, P.R. China. E-mail: jwjiao@ioz.ac.cn.

DOI:10.1523/JNEUROSCI.4129-13.2014

Copyright $\odot 2014$ the authors $\quad 0270-6474 / 14 / 345184-16 \$ 15.00 / 0$ and memory, contextual fear memory, and pattern separation (Gheusi et al., 2000; Clelland et al., 2009).

Neurogenesis is regulated by many extracellular and intracellular molecules. As the interface between the genes and the environment, epigenetic regulation is essential for the maintenance of NSCs and the generation of functional neural cell types. For instance, Bmil, a member of the Polycomb group (PcG) protein complex, is essential for maintaining the self-renewal of NSCs through the regulation of the cell cycle inhibitor, P16 (Molofsky et al., 2003; Fasano et al., 2007). Mll1, a Trithorax group member, is essential for the epigenetic transition from neural precursors to the neuronal lineage (Lim et al., 2009). Although many histone modifiers have been reported, the roles of these components in adult neurogenesis remain poorly understood.

Enhancer of zeste homolog2 (Ezh2), a subunit of the polycomb repressive complex 2, mainly acts as a gene silencer by methylating H3K27 (Margueron et al., 2009). Cortex-specific deletion of Ezh2 at E12 disrupts cortical neurogenesis and alters the timing of cortical development (Pereira et al., 2010). Ezh2 also plays a role in pushing the NSCs toward a neuronal lineage during the development. Overexpression of Ezh2 inhibits astrocyte differentiation but promotes oligodendrocyte differentiation (Sher et al., 2008). As a candidate gene, mutations in Ezh2 cause Weaver's syndrome, which is characterized by learning disabilities and general overgrowth (Tatton-Brown et al., 2011; Gibson et al., 2012). Although Ezh2 has an important function in the central nervous system, it is largely unknown whether Ezh2 is involved in adult hippocampal neurogenesis or even spatial learning and memory.

Here, we demonstrate that Ezh2 promotes the amplification of active NSCs and progenitor cells through the Pten-Akt-mTOR signaling pathway. The deletion of Ezh 2 in progenitor cells leads to the long-term decrease of neuron production in vivo. More 
importantly, Ezh2-null mice show impaired learning and memory ability. These results provide significant insight into the function of Ezh2 in adult neurogenesis and the effect of Ezh2 on spatial learning and memory.

\section{Materials and Methods}

Animals. The Ezh ${ }^{f / f}$ mice (129Sv) were kindly provided from Stuart Orkin, Harvard Medical School. The Nestin-CreERT2 mice (C57BL6) were kindly provided by Amelia Eisch, University of Texas Southwestern Medical Center. The Nestin-Cre mice (C57BL6) were obtained from The Jackson Laboratory. The Ezh2 mice information is described previously (Shen et al., 2008). The Nestin-CreERT2 mice construct and other information are also described previously (Battiste et al., 2007; Lagace et al., 2007).

The $E z h 2^{f / f}$ mice were crossed with the Nestin-Cre mice, generating

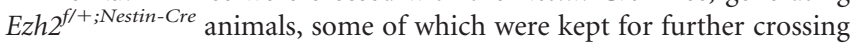
with $E z h 2^{f / f}$ mice to generate homozygous Ezh2 $2^{f / f ; N e s t i n-C r e}$, which could only survive for 15-20 d after birth.

The Nestin-Cre-ERT2 and Ezh2 f/f mice were crossed to generate Ezh2 $2^{f /+; N e s t i n-C r e E R T 2}$ animals. Ezh2 $2^{f /+; \text { Nestin-CreERT2 }}$ mice were further

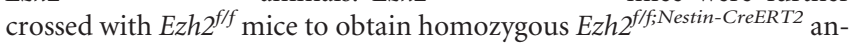
imals, which were used for the sequential experimental breeding. All of the animal used in the experiments were delivered in parallel and conducted littermate controls. Generally, mice were treated in the standard conditions ( $12 \mathrm{~h}$ light/dark cycle, except where indicated) and provided with clean-grade food and water. All the mice involved in procedures were in line with the Guide for the Care and Use of Laboratory Animals. All animal experiments and protocols were approved by the Animal Committee of Institute of Zoology, Chinese Academy of Sciences.

Mouse adult NSC cultures. The mouse adult NSC/progenitor cell isolation was according to the protocol described previously (Guo et al., 2012). Briefly, mouse brains were obtained by cervical dislocation and dissected to remove the brainstem, cerebellum, and olfactory bulbs. Brain was finely cut into five sections, and tissue involving NSCs/progenitor cells was harvested and digested in papain (Worthington) dissolved in Hibernate media for $30 \mathrm{~min}$ at $37^{\circ} \mathrm{C}$ and mechanically dissociated by pipetting tips up and down. Then NSCs/progenitor cells were purified by washing the mixture in the high-glucose DMEM (Gibco) for $5 \mathrm{~min}$ three times, $1100 \mathrm{rpm}$, and in the aNSC self-renewal/proliferation culture medium (containing DMEM/F12, Neurobasal medium, B27, GlutaMAX, and non-necessary amino acid) for $5 \mathrm{~min}$ two times, $1100 \mathrm{rpm}$, and plated in the nontreated cell culture 6-well plate (Jet Biofile).

The proliferation media consisted of Neurobasal A medium/DMEM/ F12 (Invitrogen) with penicillin-streptomycin-glutamine (Invitrogen), GlutaMAX (0.5\%; Invitrogen) and Nonessential amino acid (1\%; Invitrogen), B27 supplement (2\%; Invitrogen), bFGF (10 ng/ml; Invitrogen), and EGF (10 ng/ml; Invitrogen).The differentiation media was made up of low glucose DMEM (Gibco) with penicillin-streptomycin-glutamine, $2 \%$ B27 supplement, and $1 \%$ fetal bovine serum (Invitrogen). Cells were incubated at $37^{\circ} \mathrm{C}$ in $5 \% \mathrm{CO}_{2}$ and $20 \%$ oxygen at $95 \%$ humidity. For the cell proliferation, the medium was changed semivolume every other day for $7 \mathrm{~d}$ until neurospheres were observed.

The dissociated cells were obtained by digesting the adult NSC/progenitor cell spheres originating from the above primary cells with Accutase (Gibco), and then the aNSCs were planted at a density of 50,000 cells $/ \mathrm{ml}$ onto acid-treated glass coverslips (Deckglaser), 48-well plates (200 $\mu \mathrm{l} /$ well; Corning), 24-well plates (400 $\mu \mathrm{l} /$ well; Corning), or 6-well plates ( $2 \mathrm{ml} /$ well; Corning) in self-renewal/proliferation media for the sequential experiments. All of the above glass coverslips (Deckglaser) and plates (Corning) were coated with poly-L-ornithine (10 $\mu \mathrm{g} / \mathrm{ml}$; Sigma) and laminine ( $5 \mu \mathrm{g} / \mathrm{ml}$; Sigma).

Reagents. The following primary antibodies and dilutions were used for immunohistochemistry (IHC) staining and Western blotting: mouse monoclonal anti-BrdU (1:1000; Millipore), rat monoclonal anti-BrdU (1:1000; Abcam), rabbit monoclonal anti-Ki67(1:1000;Abcam), mouse monoclonal anti-Ezh2 (1:100; Abgent), rabbit monoclonal anti-Ezh2 (1: 1000; Cell Signaling Technology), mouse monoclonal anti-Nestin (1: 200; Millipore), mouse monoclonal anti-GFAP (1:1000; Millipore), mouse monoclonal anti-SOX2 (1:500; RD), rabbit monoclonal antiSOX2 (1:250; Millipore), mouse monoclonal anti-NeuN (1:200; Millipore), rabbit monoclonal anti-Pten (1:1000; Cell Signaling Technology), goat polyclonal anti-DCX (1:200; Santa Cruz Biotechnology), mouse monoclonal anti- $\beta$-actin (1:2000; Proteintech), rabbit monoclonal antiAkt (1:1000; Cell Signaling Technology), rabbit monoclonal antiphospho-Akt (1:1000; Cell Signaling Technology), rabbit monoclonal anti-mTOR (1:1000; Cell Signaling Technology), rabbit monoclonal anti-phospho-mTOR (1:1000; Cell Signaling Technology ), rabbit monoclonal anti-H3 (1:4000; Cell Signaling Technology), and rabbit polyclonal anti-trimethyl-Histone H3 (Lys27; 1:2000; Cell Signaling Technology ).

Tamoxifen and BrdU administration. To activate Cre-mediated recombination, tamoxifen (TAM; Sigma-Aldrich) was used, which was made fresh daily and dissolved in sunflower oil solution (Sigma-Aldrich). Fiveweek-old mice were administered $30 \mathrm{mg} / \mathrm{kg}$ prewarmed TAM daily intraperitoneally for 5 consecutive days. Five days later, mice were injected with $50 \mathrm{mg} / \mathrm{kg} \mathrm{BrdU}$ (Sigma-Aldrich) intraperitoneally seven times (once every $2 \mathrm{~h}$ ) in $1 \mathrm{~d}$ and were killed 1 week or 3 weeks later to identify BrdU-positive adult-born cells.

Immunocytochemistry on cultured cells. Cultured cells were washed with PBS (Invitrogen), fixed in 4\% PFA, blocked in 5\% BSA (in $0.1 \%$ PBST; Sangon), incubated with primary antibodies overnight at $4^{\circ} \mathrm{C}$, and visualized with secondary antibodies.

IHC on mouse brain sections. Mice were anesthetized via pentobarbital sodium intraperitoneally, perfused intracardially with ice-cold solutions of $10 \mathrm{ml}$ of $0.9 \%$ physiological saline, and then followed by $10 \mathrm{ml}$ of $4 \%$ PFA in PBS. Brains were gained and fixed in $4 \%$ PFA for $24 \mathrm{~h}$ at $4^{\circ} \mathrm{C}$, after that in $30 \%$ sucrose $/ 4 \%$ PFA overnight at $4^{\circ} \mathrm{C}$, and then followed by $30 \%$ $(\mathrm{w} / \mathrm{v})$ sucrose in $\mathrm{PBS}$ at $4^{\circ} \mathrm{C}$ until brains sunk. Brains were embedded in Tissue-Tek (Sakura) at $-20^{\circ} \mathrm{C}$ until IHC. Coronal sections $(40 \mu \mathrm{m})$ were harvested using a freezing microtome (Leica CM1950). IHC was done on $40-\mu \mathrm{m}$-thick coronal brain sections, via a free-floating antibody staining method. Briefly, brain sections were washed once with 0.1 M PBS, pH 7.4, fixed by $4 \%$ PFA, and washed by PBST ( $0.1 \%$ Triton X-100 in $0.1 \mathrm{M}$ PBS) for $15 \mathrm{~min}$ three times. Brain slices were incubated in blocking buffer $(5 \%$ BSA in $1 \%$ PBST) for $1 \mathrm{~h}$ at room temperature. Alternately, when IHC was required for BrdU visualization, brain sections were washed using PBST for 15 min three times. Sequentially, sections were subjected to $\mathrm{HCl}$ treatment, incubated in ice-cold $1 \mathrm{~N} \mathrm{HCl}$ for $10 \mathrm{~min}$, in $2 \mathrm{~N} \mathrm{HCl}$ for 10 min at room temperature, and in $2 \mathrm{~N} \mathrm{HCl}$ for $40 \mathrm{~min}$ at $37^{\circ} \mathrm{C}$. After finishing the above steps, PBST was used to wash the sections. Blocking was processed as stated above. Brain slices were incubated in primary antibodies overnight at $4^{\circ} \mathrm{C}$. Brain sections were then washed in PBST for $15 \mathrm{~min}$ three times followed by secondary antibodies conjugated with Alexa Fluor dyes (1:1000 dilution; Jackson ImmunoResearch) in PBST buffer for $1 \mathrm{~h}$ at room temperature on a platform shaker. Brain sections were washed three times for $15 \mathrm{~min}$ in PBST, incubated with $2 \mu \mathrm{g} / \mathrm{ml}$ DAPI for $2 \mathrm{~min}$, and washed three times for $5 \mathrm{~min}$ with PBST. Unless otherwise stated, all of the IHC procedures used in the experiment were delivered at room temperature. Brain sections were then mounted on adhesion microscope slides (Pan et al., 2012).

Confocal imaging. All images were captured with a Zeiss 780 laser scanning confocal microscope.

Western blotting. Adult NSCs and tissue protein extracts were obtained by lysing NSCs/tissue in RIPA (Solarbio) buffer (add PMSF, $10 \mathrm{~mm}$; mixture, $10 \mathrm{~mm}$ ). Thirty micrograms of proteins (in $4 \times$ loading buffer) was added into SDS-PAGE gels (6-15\%; Bio-Rad) and transferred onto nitrocellulose or polyvinylidene difluoride (PVDF) membranes. The membranes were incubated with primary antibodies and the primary antibody was visualized using IRDye $800 \mathrm{CW}$ or $680 \mathrm{CW}$ (LI-COR) donkey anti-mouse or anti-rabbit secondary antibodies.

RT-PCR analysis. Expression of mouse cell proliferation-associated gene transcripts was detected by total RNA reverse transcription followed by PCR analysis. The total RNA was extracted from the primary NSCs using RNA simple Total RNA Kit (Tiangen) according to the manufacturer's instructions. The first-strand cDNA synthesis was performed with FastQuant RT Kit (with DNase; Tiangen). According to the descriptions (Stambolic et al., 1998; Tetsu and McCormick, 1999; O'Carroll et al., 
A

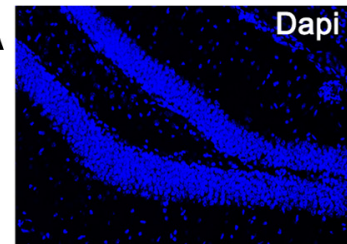

B

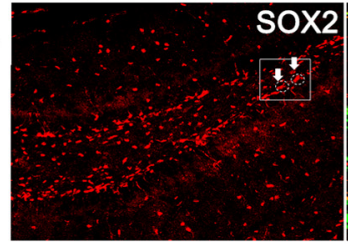

c

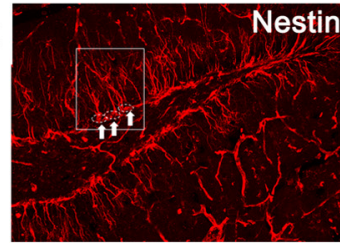

D

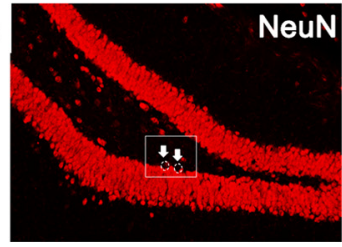

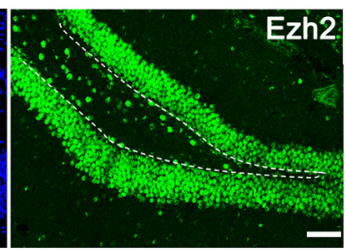
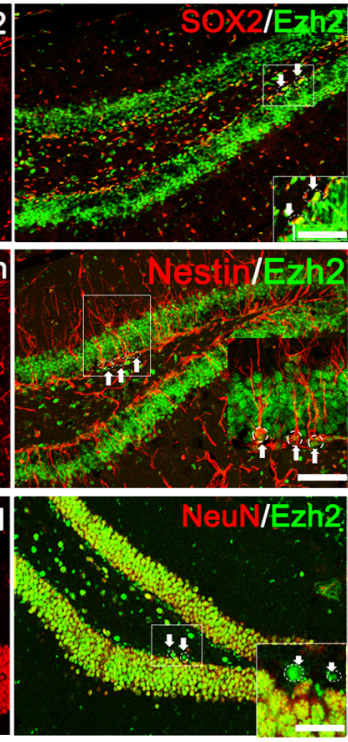

E

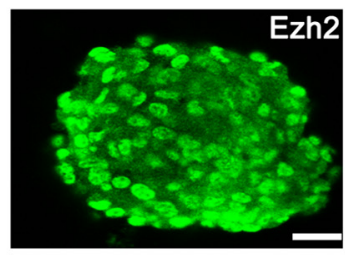

$F$

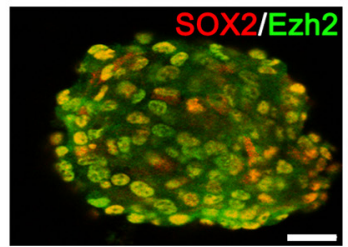

G

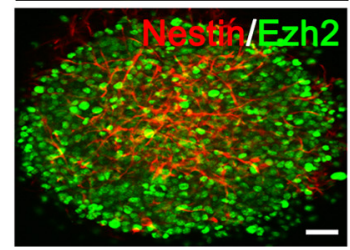

H

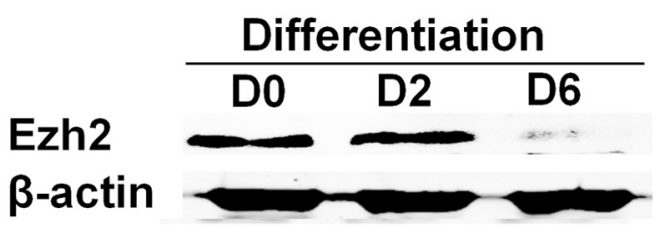

Figure 1. Ezh2 is expressed in neural progenitor cells, as well as in mature neurons in the hippocampus. $A$, Ezh2 is expressed in the DG of the hippocampus. Brain sections from 6-week-old C57 mice were evaluated using immunohistochemical analysis with antibodies against Ezh2 in the DG of the hippocampus. B, Ezh2 is expressed in Sox2 ${ }^{+}$NSCs/progenitor cells. Brain sections were stained with antibodies against Sox2 (red) and Ezh2 (green). Sox2 ${ }^{+} /$Ezh2 ${ }^{+}$cells are highlighted by the white arrowheads. C, Ezh2 is expressed in Nestin ${ }^{+}$NSCs/progenitor cells. Brain sections were stained with antibodies against Nestin (red) and Ezh2 (green). White arrowheads show Nestin ${ }^{+} /$Ezh2 $^{+}$cells. D, Ezh2 is expressed in a subset of NeuN ${ }^{-}$cells. Brain sections were stained with antibodies against NeuN (red) and Ezh2 (green). White arrowheads show NeuN ${ }^{-} /$Ezh2 ${ }^{+}$cells. E, Ezh2 is expressed in in vitro cultured progenitor cells. Primary NSCs/progenitor cells were isolated from the DG of 6-week-old 57 mice and cultured into neurospheres 1 week later. Immunocytochemical analysis was performed on neurospheres or freshly dissociated progenitor cells with antibodies against Ezh2. Scale bar, $50 \mu \mathrm{m}$. F, Ezh2 is colabeled with Sox2 in neurospheres and dissociated progenitor cells. G, Ezh2 is colabeled with Nestin in neurospheres and dissociated progenitor cells. $\boldsymbol{H}$, Western blot analysis showed that Ezh2 is decreased in differentiated progenies. Protein lysates of dissociated progenitor cells in self-renewing conditions (day 0 ) or in differentiation conditions for increasing lengths of time (days 2 and 6 ) were probed with antibodies against Ezh2 and $\beta$-actin.

2001; Kausch et al., 2003; Mangi et al., 2003) and primer bank, the sequences of primers used are as follows: Cyclin D1 (Forward: $5^{\prime}$ TAGGCCCTCAGCCTCACTC-3'; Reverse: 5'-CCACCCCTGGGA TAAAGCAC-3'), EED (Forward: 5'-ATGCTGTCAGTATTGAGAG TGGC-3'; Reverse: 5' - GAGGCTGTTCACACATTTGAAAG-3'), Ezh1 (Forward: 5' -TGAAATCTGAGTATATGCGGC-3'; Reverse: 5'-AGATATCCTGGCTGTCGAAC-3'), Ezh2 (Forward: 5'-GCCAGACTG GGAAGAAATCTG-3'; Reverse: 5' -TGTGCTGGAAAATCCAAG-3'), Ki67 (Forward: 5' -CTTTGGGTGCGACTTGACG-3'; Reverse: 5' GTCGACCCCGCTCCTTTT-3'), Pten (Forward: 5'-GGATCCGACATGACAGCCATCATCAAAG-3'; Reverse: 5'-CTCGAGTCAGACT TTTGTAATTTGTGAATGCTG-3'), Akt (Forward: 5' -AACGGA CTTCGGGCTGTG-3'; Reverse: 5' -TTGTCCTCCAGCACCTCAGG$3^{\prime}$ ), $\beta$-actin (Forward: $5^{\prime}$-GGTGGGAATGGGTCAGAAGG-3'; Reverse: 5'-AGGAAGAGGATGCGCCAGTG-3').

Cell cycle analysis by flow cytometry. Adult NSCs infected by the virus were harvested and fixed with $70 \%$ ethanol for $12 \mathrm{~h}$ at $4^{\circ} \mathrm{C}$. Analysis of the cell cycle phases was performed with propidium iodide ( $50 \mu \mathrm{g} / \mathrm{ml}$, containing $100 \mu \mathrm{g} / \mathrm{ml}$ RNase A) staining and analyzed by FACSCalibur cytometer (Becton Dickinson) according to the manufacturer's instructions (Liu et al., 2010; Mira et al., 2010).

Stereotaxic gene delivery in the mouse brain. Briefly, retroviral DNA was transfected into Plat-GP cells with the packaging plasmids pCMV-Vsvg mediated by GenEscort I (Wisegen). The medium with retrovirus was harvested at 24,48 , and $72 \mathrm{~h}$ post-transfection, centrifuged at $3000 \mathrm{rpm}$ for $5 \mathrm{~min}$ to get rid of cell debris, and concentrated using RetroConcentin virus Precipitation Solution (SBI). Retroviral injections in vivo were conducted by methods described previously (Zhao et al., 2006; Smrt et al., 2007; Liu et al., 2010). Briefly, 6-week-old Ezh2 $2^{\text {f/f }}$ male mice were anesthetized with pentobarbital sodium and concentrated virus $\left(\sim 1 \mu\right.$ l with titer $\left.\geq 5 \times 10^{5} / \mu \mathrm{l}\right)$ was injected stereotaxically into the SGZ of hippocampus with the following coordinates relative to bregma: anteroposterior, $2.0 \mathrm{~mm}$; lateral, $1.5 \mathrm{~mm}$; depth, $2.25 \mathrm{~mm}$. For each mouse, the control virus was injected stereotaxically into the left SGZ, and the Cre virus was injected into the right SGZ. Five days after virus injection, mice were administrated $\mathrm{BrdU}$ ( $50 \mathrm{mg} / \mathrm{kg}$, i.p.) for a total of seven times in one day (once every $2 \mathrm{~h}$ ). One week after viral grafting, mice were given deep anesthetization with pentobarbital sodium and then killed as described previously (Cetin et al., 2006; Liu et al., 2010; Mira et al., 2010).

Chromatin immunoprecipitation. In this study, H3K27me3 antibody was used for chromatin immunoprecipitation (ChIP) assay. Cells were treated with $1 \%$ formaldehyde at room temperature for $15 \mathrm{~min}$ and then $2.5 \mathrm{M}$ glycine added to stop the reaction. After rinsing three times with cold PBS, cells were harvested in lysis buffer 1 (50 mM HEPES-KOH, pH 7.5, $140 \mathrm{~mm} \mathrm{NaCl}, 1 \mathrm{~mm}$ EDTA, 10\% glycerol, 0.5\% NP-40, 0.25\% Triton, Roche protease inhibitor cocktail, and $1 \mathrm{~mm}$ PMSF), and then resuspended in lysis buffer 2 (10 mm Tris-HCl, pH 8.0, $200 \mathrm{~mm} \mathrm{NaCl}, 1 \mathrm{~mm}$ EDTA, $0.5 \mathrm{~mm}$ EGTA, Roche protease inhibitor cocktail, and $1 \mathrm{~mm}$ PMSF). After centrifugation, each sample was resuspended and sonicated in lysis buffer 3 (10 mm Tris-HCl, $\mathrm{pH} 8.0,100 \mathrm{~mm} \mathrm{NaCl}, 1 \mathrm{~mm}$ EDTA, $0.5 \mathrm{~mm}$ EGTA, $0.1 \%$ sodium deoxycholate, $0.5 \% \mathrm{~N}$ lauroylsarcosine, Roche protease inhibitor cocktail, and $1 \mathrm{~mm}$ PMSF). Lysates were incubated with $50 \mu \mathrm{l}$ of Dynabeads Protein A (Invitrogen) preloaded with $1 \mu \mathrm{g} \mathrm{H} 3 \mathrm{~K} 27 \mathrm{me} 3$ antibody overnight at $4^{\circ} \mathrm{C}$. After washing five times with wash buffer (50 mM HEPES-KOH, pH7.5, $500 \mathrm{~mm}$ LiCl, 1 mm EDTA, 1\% NP-40, and 0.7\% sodium deoxycholate), Dynabeads Protein $\mathrm{A}$ was heated at $65^{\circ} \mathrm{C}$ to reverse the covalent histone-DNA bonds. DNA was extracted by DNA Gel Extraction Kit and used for 

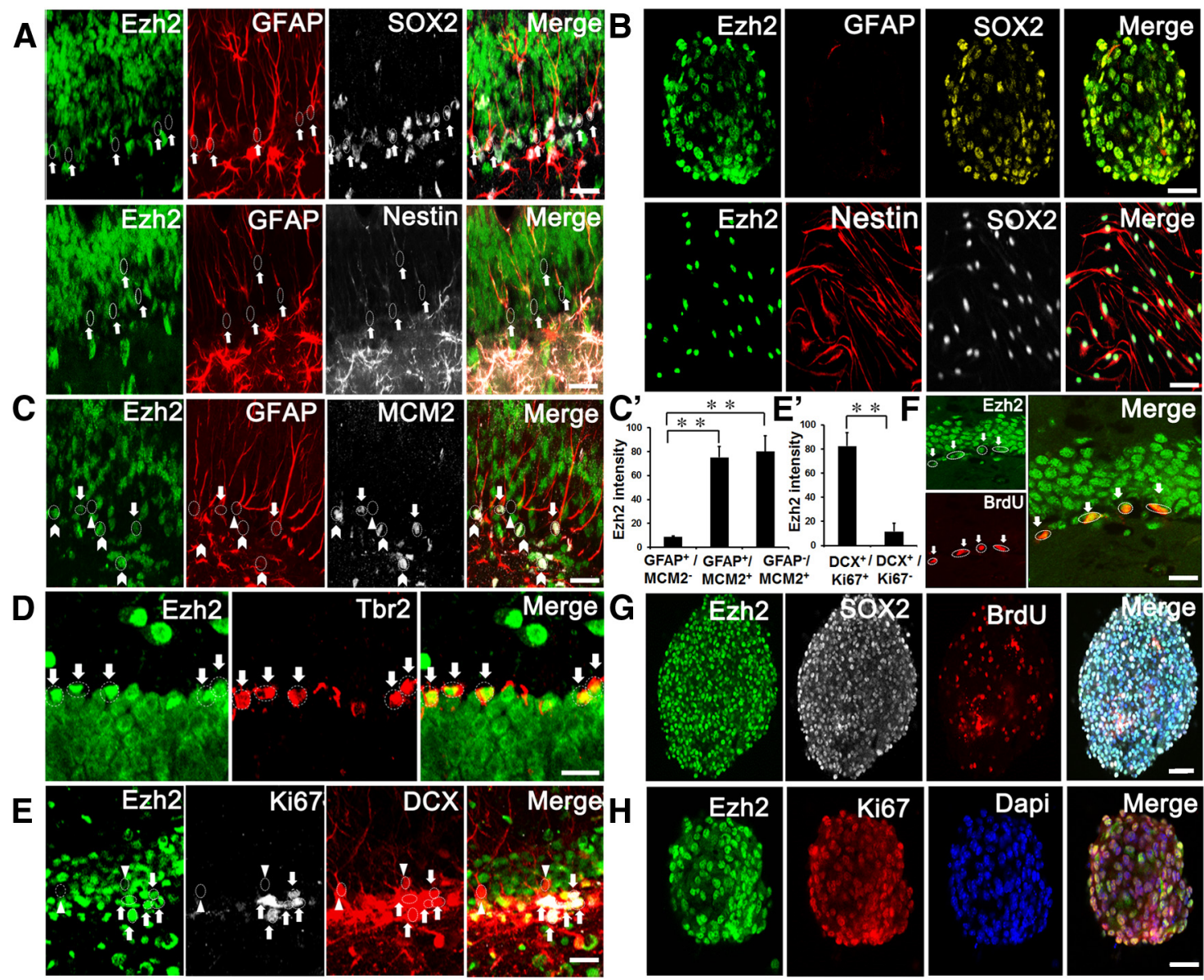

Figure 2. Ezh2 is expressed in neural progenitor cells but not in quiescent NSCs. A, Ezh2 is not expressed in the majority of radial glia-like cells. Confocal microscopy images of adult hippocampal sections of cells triple labeled for Ezh2 (green), Sox2 or Nestin (white), and GFAP (red). The arrowheads show the Ezh2-negative, but Sox2/Nestin and GFAP double-positive cells. B, Ezh2 is expressed in progenitor cells but not in quiescent NSCs in vitro. Neurospheres were stained with Ezh2 (green), GFAP (red), and Sox2 (yellow). Disassociated cells were labeled with Ezh2 (green), Nestin (red), and Sox2 (white). C, Ezh2 is expressed in active NSCs/progenitor cells but not in quiescent NSCs. Brain sections was triple labeled for Ezh2 (green), GFAP (red), and MCM2 (white). The white arrowheads show Ezh2 ${ }^{+} \mathrm{GFAP}^{+} \mathrm{MCM2}^{+}$cells (active NSCs cells) whereas the white triangles show Ezh2 ${ }^{-} \mathrm{GFAP}^{+} \mathrm{MCM2}^{-}$cells (quiescent NSCs). The solid arrowhead arrows show Ezh2 ${ }^{+} \mathrm{GFAP}^{-} \mathrm{MCM}^{+}$progenitor cells. The staining intensity of Ezh2 was quantified in GFAP ${ }^{+} \mathrm{MCM2}{ }^{-}$cells, GFAP ${ }^{+} \mathrm{MCM2}^{+}$cells, and GFAP ${ }^{-} \mathrm{MCM2}^{+}$cells $\left(\boldsymbol{C}^{\prime}\right)$. $\boldsymbol{D}$, Ezh2 is expressed in transit-amplifying intermediate progenitor cells in the SGZ. Double labeling of Ezh2 (green) and Tbr2 (red) in the adult hippocampal sections. E, Ezh2 is more highly expressed in neuroblasts than in immature neurons. Adult hippocampal section was labeled by Ezh2 (green), DCX (red), and Ki67 (white). The white arrowheads show Ezh2 ${ }^{+}$DCX ${ }^{+}$Ki67 ${ }^{+}$cells (neuroblasts) whereas the white triangles show Ezh2 ${ }^{-} \mathrm{DCX}{ }^{+} \mathrm{Ki} 67^{-}$cells (immature neurons). The staining intensity of Ezh2 were measured in $\mathrm{DCX}{ }^{+} / \mathrm{Ki} 67^{+}$cells and DCX ${ }^{+} \mathrm{Ki} 67^{-}$cells $\left(\boldsymbol{E}^{\prime}\right)$. $\boldsymbol{F}$, Ezh2 staining was detected in proliferating progenitor cells labeled with BrdU. Coimmunostaining of Ezh2 (green) and BrdU (red) in the SGZ. G, Ezh2 is expressed in proliferating progenitor cells in neurospheres. Neurospheres were triple labeled with Ezh2 (green), Sox2 (white), and BrdU (red). $\boldsymbol{H}$, Ezh2 is highly expressed in cells that are in the cell cycle of neurospheres. Neurospheres were colabeled with Ezh2 (green) and Ki67 (red). The nuclei were stained with DAPI (blue). Scale bar, $50 \mu \mathrm{m}$.

real-time PCR. Primers used in real-time PCR were as follows: Pten coding sequence: forward: TGTGGTCTGCCAGCTAAAGT; reverse: ACATGAACTTGTCCTCCCGC (Yoshimi et al., 2011); Pten promoter: forward: TGACTACTATCCTCCGGATTTCTAA; reverse: TGAGCCCTAAAGTATCTCTGAGTTG (Feng et al., 2013).

Open-field test and habituation. The open-field apparatus, a wooden square box $(90 \mathrm{~cm} \times 90 \mathrm{~cm})$ with a $45 \mathrm{~cm}$ high wall, was used to analyze the locomotor activity and anxiety level. Prehabituation was not done in the arena. Ezh2 $2^{f / f \text {; }}$ stin-CreERT2 mice were individually put into the center of the arena with the Photo Beam Tracking System and allowed to explore the box freely for $15 \mathrm{~min}$. Meanwhile, the distance traveled (meters), time spent in the center (seconds), and time spent in the periphery (seconds) were recorded (Pan et al., 2012; Soares et al., 2013). Data were collected and analyzed using SMART v2.5.21 software (Panlab; Harvard Apparatus).

Morris water maze assay. The procedure was instructed by previously described protocols (Vorhees and Williams, 2006; Zhang et al., 2008a, b). Ezh2 $2^{f / f \text { Nestin-CreERT2 }}$ mice given 5 consecutive days of TAM or vehicle treatment were delivered to the Morris water maze to estimate their spatial learning and memory ability. Morris maze for mice contains two parts: a circular tank $(120 \mathrm{~cm}$ in diameter, $25 \mathrm{~cm}$ in depth) and an escape platform (10 cm in diameter), a kind of hyaline Plexiglas settled in a stable location for the entire training session. Target escape platform is usually submerged $1 \mathrm{~cm}$ lower than the surface of the opaque water. Nontoxic titanium dioxide white paint was used to make the water opaque so that the platform is hidden. Water temperature was controlled at $21 \pm 1^{\circ} \mathrm{C}$ throughout the entire training and testing procedures. Four extra-maze cues, in different shapes, colors, and sizes, were uniformly located on the wall surrounding the water tank. During the probe trial, mice were trained in four trials (60 s per trail) per day starting from different sites. Signal mouse was gently released into one of the desired zones without the platform, facing the tank wall, and allowed to swim for $60 \mathrm{~s}$ to spot the escape platform. Mice that failed to find the hidden platform during the $60 \mathrm{~s}$ were introduced gently to the hidden platform and allowed to rest on the platform for $15 \mathrm{~s}$. On subsequent days, the trials were repeated for 8 consecutive days. During the training session, a total of 32 trials were delivered (four trials per day for $8 \mathrm{~d}$ ).

For the probe test, the platform was removed and the probe trail was conducted $24 \mathrm{~h}$ after the last training trial. The animal was put into a 


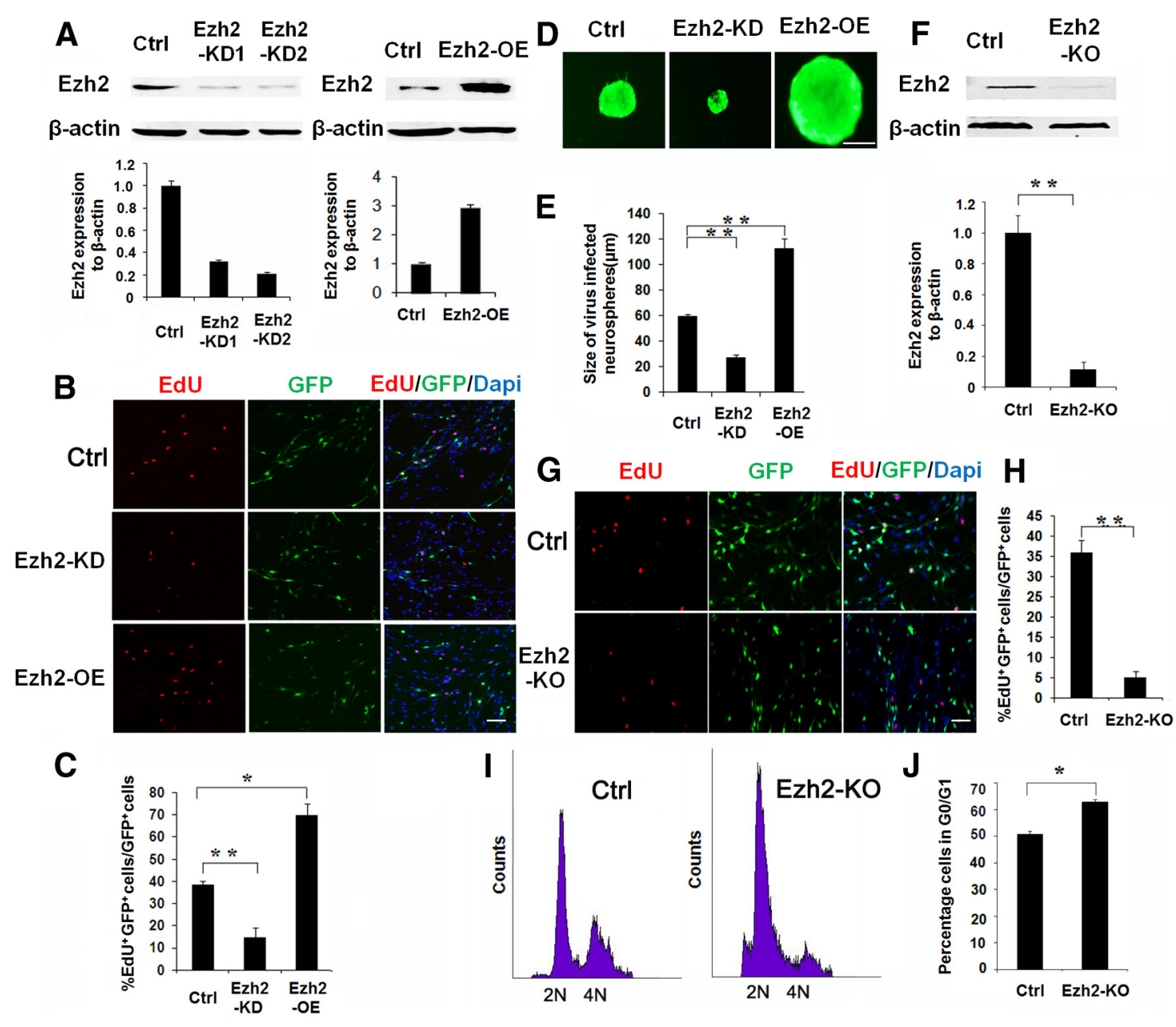

Figure 3. Ezh2 regulates the proliferation of primary NSCs/progenitor cells isolated from adult DG. $A$, Western blot analysis showed Ezh2 was effectively suppressed by RNA interference or was upregulated after Ezh2 overexpression. Primary NSCs/progenitor cells were infected with control, Ezh2 shRNA, or Ezh2 overexpression retrovirus. The cell lysates were probed with anti-Ezh2 and $\beta$-actin antibodies. B, Proliferation analyses showed that Ezh2 promoted the proliferation of primary NSCs/progenitor cells. Cells infected with control, Ezh2 shRNA, or Ezh2 overexpression retrovirus (GFP) were labeled with EdU (red) and then stained. Scale bar, $100 \mu \mathrm{m}$. C, Quantitative analysis showed that there was a higher percentage of EdU incorporation in the Ezh2 overexpressed progenitor cells compared with the control cells, as well as a lower percentage of EdU incorporation in the Ezh2 knockdown progenitor cells. D, Neurospheres were grown for $7 \mathrm{~d}$ after retrovirus infection. The increase in sphere size in the Ezh2 retrovirus-infected progenitor cells was apparent, whereas a decrease in sphere size in the Ezh2-shRNA retrovirus-infected progenitor cells was also observed. Scale bar, $50 \mu \mathrm{m}$. $\boldsymbol{E}$, Statistical analysis of the diameters of neurospheres generated at very low densities (one cell per $2 \mu$ l of medium) after being infected with retrovirus. $\boldsymbol{F}$, Western blot analysis showed that Ezh2 was reduced in the Cre recombinase-expressing progenitor cells. Cells were infected with control or Cre retrovirus. The cell lysates were probed with anti-Ezh2 and $\beta$-actin antibodies. $\boldsymbol{G}$, Confocal images showed the selective deletion of Ezh 2 in the Cre recombinase-expressing cells, as well as the reduced proliferation of the progenitor cells. Proliferating progenitor cells were labeled with EdU (red). Scale bar, $100 \mu \mathrm{m}$. $\boldsymbol{H}$, Quantitative comparison showed that the number of EdU-positive progenitor cells in the Cre recombinase retrovirus-infected cells was smaller than in the control cells. $I$, Flow cytometry analysis showed that deletion of Ezh2 resulted in an increase in the percentage of cells in $G_{0} / G_{1}$ phase. J, Quantification of the percentage of cells in $\mathrm{G}_{0} / \mathrm{G}_{1}$ phase. Value represents mean \pm SEM. Student's $t$ test; ${ }^{*} p<0.05,{ }^{* *} p<0.01$.

novel start site, facing the tub wall opposite the original platform location.

Reversal training followed after the probe trials for a total of 24 trials (four trials per day for $6 \mathrm{~d}$ ), in which the platform was relocated to the opposite zone and another set of 24 trials (four trials per day for $6 \mathrm{~d}$ ) was performed. Reversal probe test was administered $24 \mathrm{~h}$ after the last trial of reversal training. Later, a visible platform test was done, in which a visible platform was relocated above the water surface in a new quadrant not including the original or reversal zone. Mice were allowed to swim to search for the visible platform. A video tracking system (SMART Video Tracking System) was used to record the number of times a mouse crossed the original location of the platform, the distance traveled, latency to locate the hidden platform, and swimming speed. All data were analyzed using SMART v2.5.21 software (Panlab; Harvard Apparatus; Kohman et al., 2013).

Cued and contextual fear conditioning. This procedure was performed based on previously published protocols (Graves et al., 2003; Pollak et al., 2010; Guo et al., 2011; Pan et al., 2012). Briefly, mice were placed in a
$25 \times 25 \times 40 \mathrm{~cm}$ (height) square-shaped apparatus, equipped with a metal grid shock floor (Panlab; Harvard Apparatus). Before the formal experiment, mice were carried into the training room to habituate the environment for $7 \mathrm{~d}$.

Training. A single mouse was placed in the training context (with solid black wall) and allowed to explore freely for $2 \mathrm{~min}$, followed by conditioned stimulus (CS)-a $90 \mathrm{~dB}$ tone-which lasted for $30 \mathrm{~s}$. At the final $2 \mathrm{~s}$ of CS, an unconditioned stimulus (US)-a $0.7 \mathrm{~mA}$ footshock-was delivered. The CS and US were presented automatically with a tone generator and shocker managed by SMART v2.5.21 software (Panlab; Harvard Apparatus). Mice were then carried back to the home cages.

Testing. Twenty-four hours after training, mice performed both contextual fear-conditioning and cued tests. For the contextual fearconditioning test, a single mouse was placed in the original contextual arena without footshock, lasting for $2 \mathrm{~min}$. After $2 \mathrm{~h}$ of the contextual test, the cued test was performed. A single mouse was placed in a new context (with white wallpaper) and permitted to explore freely for $2 \mathrm{~min}$. Then the CS (tone) was delivered lasting for $2 \mathrm{~min}$. Freezing behavior was 
A

\section{$E z h 2^{f / f} \quad E z h 2^{f / f ; N e s t i n-C r e ~}$}
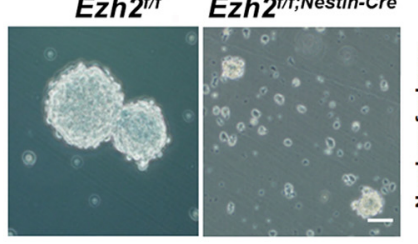

B

E
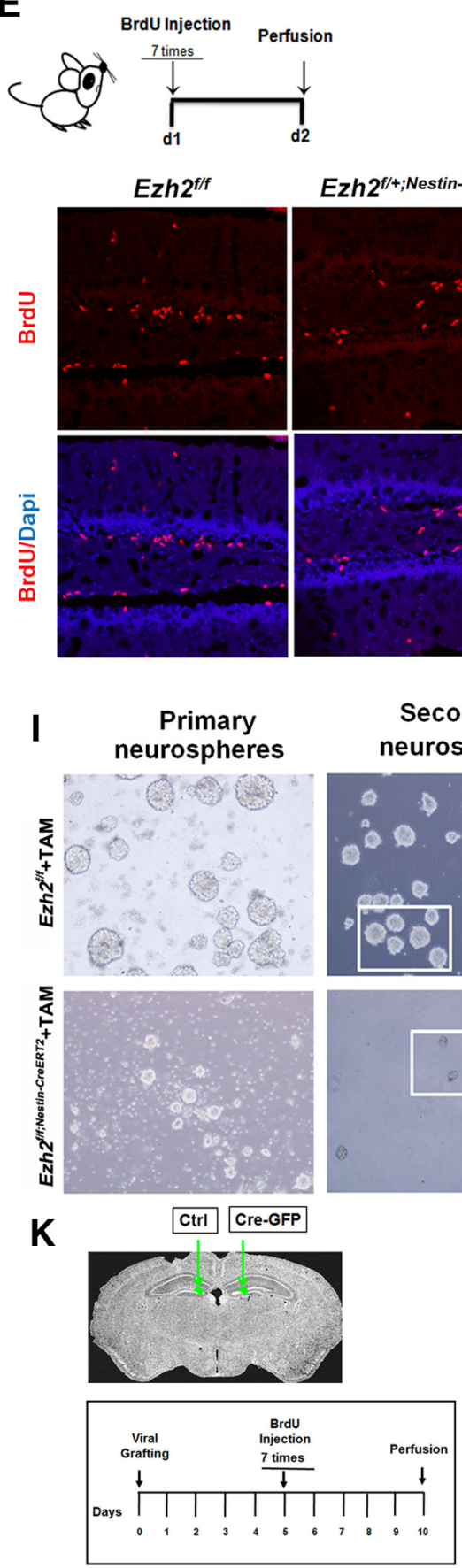
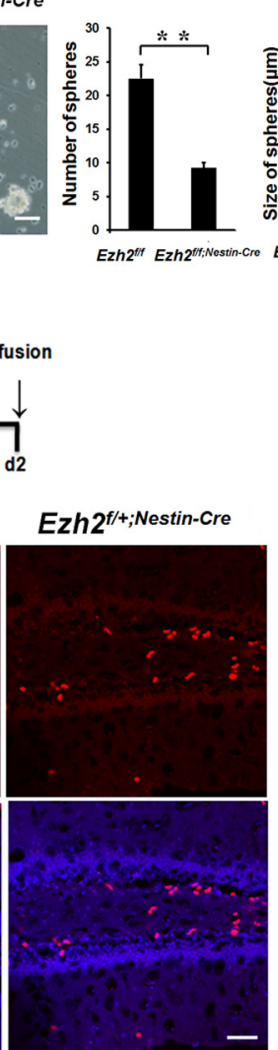

$\mathbf{F}$
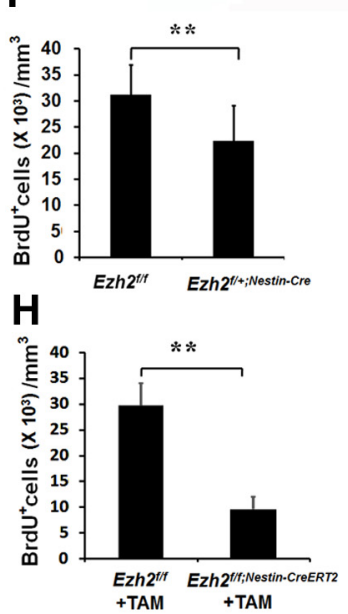

Secondary neurospheres
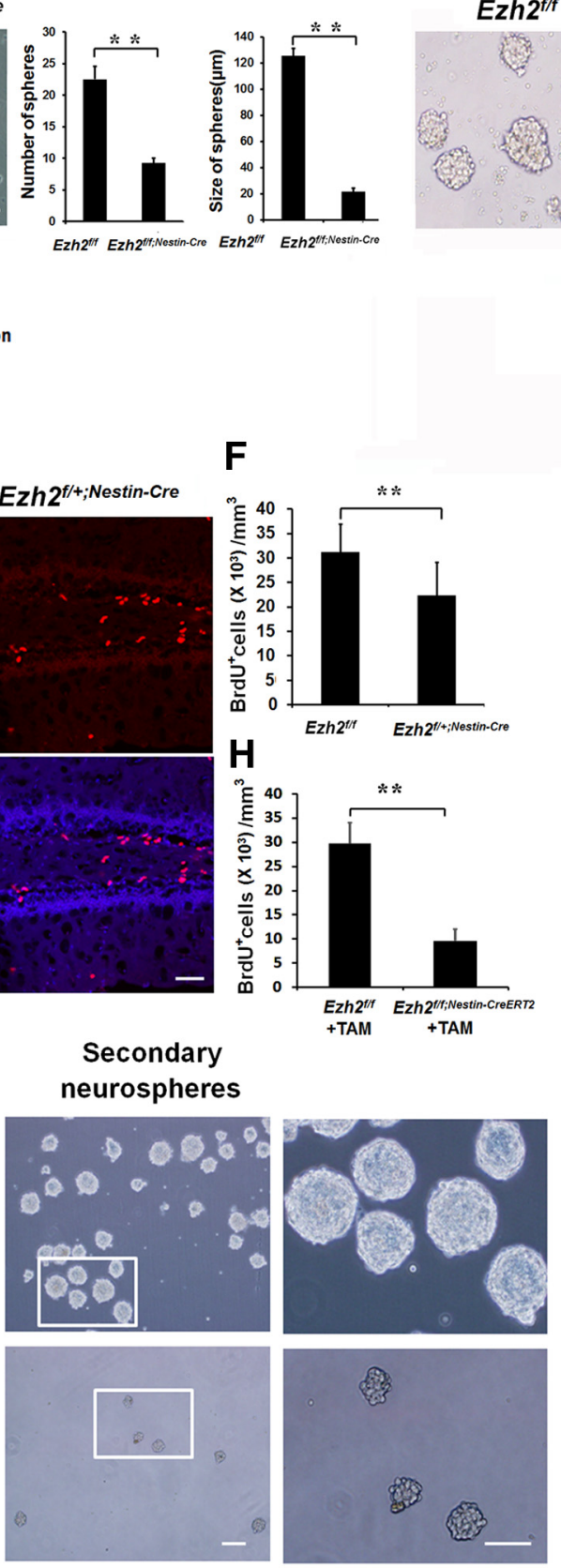

D

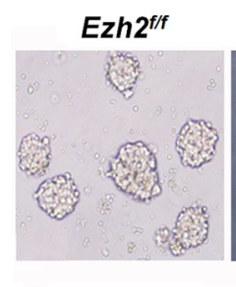

Ezh2 $2^{f /+; N e s t i n-C r e ~}$

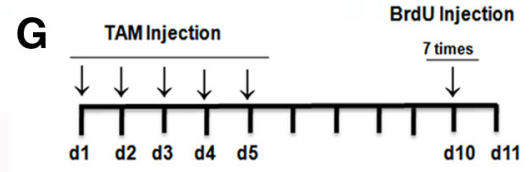

$E z h 2^{f / f}+$ TAM Ezh2 $2^{f / f ; N e s t i n-C r e E R T 2}+$ TAM
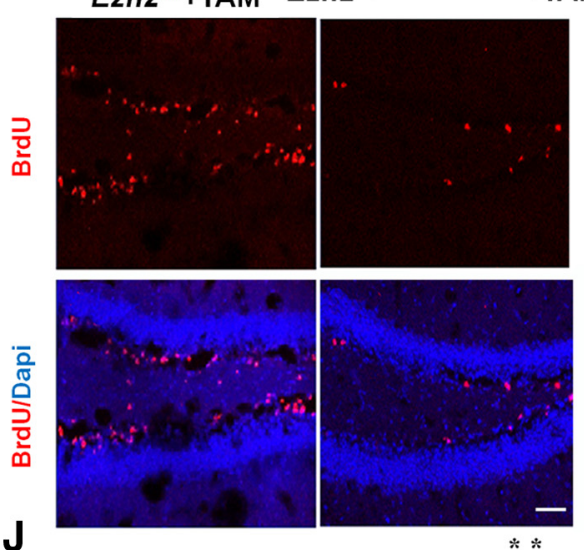

J
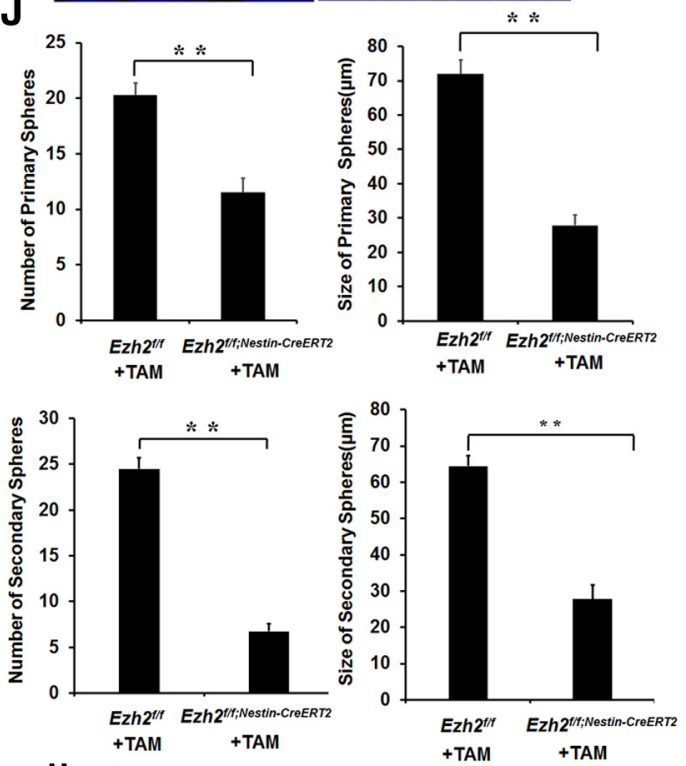
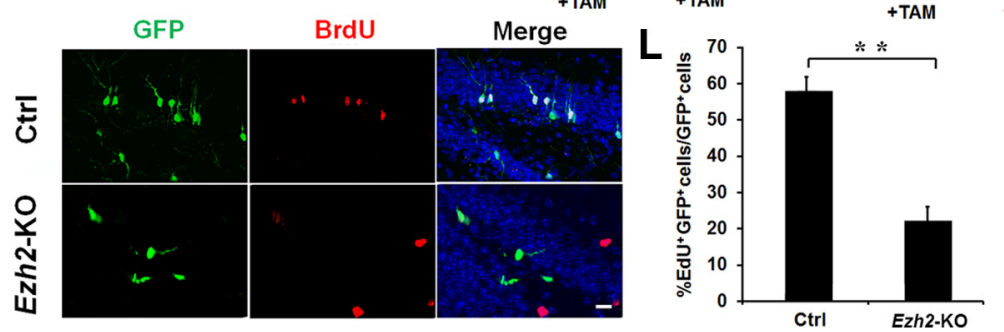

Figure 4. Deficient progenitor cell proliferation in the adult hippocampus after Ezh2 deletion. $A$, NSCs/progenitor cells isolated from Ezh $2^{f / f \text {;Nestin-Cre }}$ mice displayed a defect in primary neurosphere formation. The number of neurospheres was counted 1 week after the NSCs/progenitor cells were isolated from Ezh $2^{f / f \text {;Nestin-Cre }}$ mice and Ezh2 ${ }^{f / f}$ littermates. Scale bar, $100 \mu$ m. $\boldsymbol{B}$, NSCs/progenitor cells isolated from Ezh2-deficient mice formed neurospheres at a lower frequency and with a smaller size than those from control mice. The number and size of the neurospheres formed after 1 week were counted and measured. C, NSCs/progenitor cells isolated from Ezh $2^{f /+; N e s t i n-C r e}$ mice also displayed a defect in primary neurosphere formation. The number of neurospheres was counted 1 week after the NSCs/progenitor cells were isolated from the Ezh2 ${ }^{f /+; N e s t i n-C r e}$ mice and Ezh $2^{f / f}$ littermates. Scale bar, $100 \mu \mu \mathrm{m}$. D, NSCs/progenitor cells isolated from Ezh $2^{f /+; N e s t i n-C r e}$ mice formed neurospheres at a lower frequency and with a smaller size than those from the control mice. The number and size of the neurospheres formed after 1 week (Figure legand continues.) 
recorded by SMART v2.5.21 software for the two tests. Data were collected and analyzed by SMART v2.5.21 software. Seventy percent ethanol was used to clean the apparatus to eliminate the odor between each mouse.

Pattern separation assay. Pattern separation assay was conducted according to the previously published method (Guo et al., 2011; Sebastian et al., 2013) with minor changes. The experiment was performed using the eight-arm radial maze, which was made up of an octagonal-formed center zone $(20 \mathrm{~cm}$ in diameter, $15 \mathrm{~cm}$ in height) and eight arms [ $(30 \times$ $5 \times 15 \mathrm{~cm}$ (height)], sticking out of the center arena. The arms are made of white medical organic material. Before the assay, mice were given a calorie-restricted diet for $4 \mathrm{~d}$ to decrease mice weight to $85-90 \%$. Four trials per day for 5 consecutive days and test sessions were performed on the last day of training. A 30 min interval was performed between each trail constituted with a training phase and a choice phase. In the training phase, blocking six of the eight arms, leaving the sample arm and start arm open, and $90^{\circ}$ rotating were performed. Bait cheese was located at the end of the sample arm or test arm. Calorie-restricted mice were put in the maze, facing the wall of the start arm end, and were allowed to explore freely for $3 \mathrm{~min}$, so that they could make a choice in the maze and were given $60 \mathrm{~s}$ to eat before being carried to their home cage. Mice that failed to find the bait during the 3 min were conducted to the sample arm and permitted to eat for $60 \mathrm{~s}$ on the first $2 \mathrm{~d}$. On the sequential $3 \mathrm{~d}$, mice that made an incorrect choice were removed immediately from the maze and were not allowed access to bait. Within $3 \mathrm{~min}$, a test arm entering was scored as a correct choice, and a sample arm entering or a start arm re-entering was scored as an incorrect choice. After each phase, the maze was rotated $45^{\circ}$, cleaned with $75 \%$ ethanol to eliminate the odor reference, and then the choice phase test was performed consecutively. In this phase, opening the new sample and start arms and blocking the original one were performed, keeping the relative location of the arms unchanged in the training phase. Additionally, a test arm was defined as either one arm (separation 2) or three arms (separation 4) from the new sample one. Each mouse was conducted to the separation 2 or separation 4 tests each day. During the choice phase, correct or incorrect choices were scored manually.

Statistical analysis. Statistical analyses between two groups were performed by Student's $t$ test. All of the data were mean \pm SEM. Probabilities of $p<0.05$ were considered as significant (n.s., not significant, $p \geq$ $\left.0.05 ;{ }^{*} p \leq 0.05 ;{ }^{* *} p \leq 0.01 ;{ }^{* * *} p \leq 0.001\right)$. The behavioral data were analyzed by one-way ANOVA.

\section{$\leftarrow$}

(Figure legand continued.) were counted and measured. $\boldsymbol{E}$, Progenitor cell proliferation capabil-

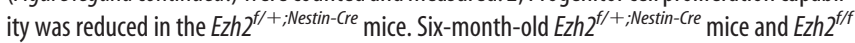
littermates were injected with BrdU seven times in $1 \mathrm{~d}$ (once every $2 \mathrm{~h}$ ) and were killed $1 \mathrm{~d}$ after the last BrdU injection. The brain sections were stained with anti-BrdU (red). The nuclei were stained with DAPI (blue). Scale bar, $100 \mu \mathrm{m}$. F, Quantification of the BrdU-positive cells in the SGZ of Ezh $2^{f /+; N e s t i n-C r e}$ mice and Ezh2 $2^{f / f}$ mice. The number of BrdU-positive cells in the SGZ was normalized to the GCL volume. $\mathbf{G}$, Progenitor cell proliferation was reduced in the Ezh2 icKO mice. Six-month-old Ezh $2^{f / f ; N e s t i n-\text { CreERT2 }}$ mice and littermates were treated with tamoxifen for $5 \mathrm{~d}$ and were injected with BrdU seven times on the fifth day after the last tamoxifen injection. Sections of the DG were stained with a proliferation marker (red). Scale bar, $100 \mu \mathrm{m}$. H, Quantification of the BrdU-labeled cells in the adult hippocampus after the inducible deletion of Ezh2. The number of BrdU-positive cells in the SGZ was normalized to the GCL volume.I, Both primary and secondary neurosphere formation was impaired after conditional Ezh2 deletion. The last section shows images taken from the boxed regions in the middle. NSCs/progenitor cells were isolated from Ezh $2^{\text {ff; } \text { Nestin-CreERT2 }}$ mice after $5 \mathrm{~d}$ of tamoxifen injection and were cultured into primary neurospheres 1 week later. The dissociated cells from the primary neurospheres formed secondary neurospheres after 1 week. Scale bar, $100 \mu \mathrm{m}$. J, Quantitative comparison of neurosphere formation in Ezh2 icKO mice and Ezh2 $2^{f / f}$ mice. $\boldsymbol{K}$, Ezh2 deletion in Ezh2 $2^{f / f}$ mice, mediated by Cre recombinase, resulted in reduced BrdU incorporation. Concentrated retroviruses expressing the control or Cre recombinase were injected stereotaxically into the left and right DG of the Ezh $2^{f / f}$ mice, respectively. Scale bar, $100 \mu \mathrm{m}$. L, Quantitative comparison of the BrdU-positive progenitor cells that were infected with retrovirus. Value represents mean \pm SEM. Student's $t$ test; ${ }^{*} p<0.05,{ }^{* *} p<0.01$.

\section{Results}

Ezh2 is expressed in neural progenitor cells as well as in mature neurons in the hippocampus

To investigate the expression of Ezh2 in the SGZ, brain sections of adult mice were stained. We found that Ezh2 was expressed in the DG of the hippocampus (Fig. 1A). To determine whether Ezh2 is expressed in the progenitor cells, coimmunostaining of Ezh2 with Sox2 or Nestin was performed. Results show that Ezh2 is expressed in Sox2-positive cells and Nestin-positive cells in the SGZ (Fig. 1B,C). Moreover, Ezh2 immunoreactivity was detected not only in NeuN-positive cells but also in a subset of NeuN-negative cells (Fig. 1D). These results indicate that Ezh2 is expressed in neural progenitor cells, as well as in mature neurons in the hippocampus.

To confirm the expression of Ezh2 in vitro, adult NSCs/progenitor cells isolated from the SGZ were cultured into neurospheres. Immunostaining assays revealed that Ezh2 is also expressed in neurospheres and dissociated NSCs/progenitors (Fig. 1E). Consistent with the findings in vivo, Ezh2 is coexpressed with Sox2 or Nestin (Fig. 1F,G).

To assess the expression level of Ezh2 in NSCs/progenitors, differentiated progenies in vitro were used for comparison. Western blot results suggested that the expression of Ezh2 is higher in NSCs/progenitors than in differentiated progenies, which were cultured in differentiation conditions for $1-6 \mathrm{~d}$ (Fig. 1H).

\section{Ezh2 is expressed in active NSCs/progenitor cells, but not in quiescent NSCs}

To identify the Ezh2-expressing cell population in NSCs/progenitor cells, we performed coimmunostaining of Ezh2 with various cellular markers. NSCs in the DG express both GFAP and Sox2, with radial fibers spanning the granule cell layer. Significantly, Ezh2 was not detected in the vast majority of NSCs (GFAP ${ }^{+}$ Sox $2^{+}$radial fiber ${ }^{+}$cells; Fig. $2 A$ ). Consistent expression patterns were observed in the NSCs/progenitor cells cultured in vitro (Fig. 2B). Meanwhile, Ezh2 immunoreactivity was detected in $\mathrm{GFAP}^{+} \mathrm{MCM}^{+}{ }^{+} \mathrm{NSCs}$ and $\mathrm{GFAP}^{-} \mathrm{MCM}^{+}$progenitor cells, but not in $\mathrm{GFAP}^{+} \mathrm{MCM}^{-}{ }^{-}$NSCs (Fig. 2C). In addition, most Tbr2-positive cells expressed Ezh2 (Fig. 2D), demonstrating that Ezh2 was expressed in transit amplifying intermediate progenitor cells. All above data indicated that Ezh2 was expressed in active NSCs/progenitor cells, but not in quiescent NSCs. To detect the expression of Ezh2 in neuroblasts and immature neurons (Lie et al., 2005), we performed costaining of Ezh2, Ki67, and DCX. Ezh2 immunoreactivity was more intense in $\mathrm{DCX}^{+} \mathrm{Ki}^{+}{ }^{+}$cells than in $\mathrm{DCX}^{+} \mathrm{Ki}^{-}$cells, indicating the higher expression of Ezh2 in neuroblasts than in immature neurons (Fig. 2E). Because Ezh2 was expressed in most active progenitor cells, we next analyzed the expression of Ezh2 in proliferating cells by staining cells for Ezh2 and BrdU, a proliferation marker. In the SGZ, Ezh2 was colabeled with BrdU in most of the cells, indicating that Ezh2 was expressed in most fast-dividing cells (Fig. $2 F$ ). In support of this result, we observed that Ezh2 was coexpressed with Ki67 or colabeled with BrdU in neurospheres (Fig. 2G,H).

Collectively, the above results indicate that Ezh2 is preferentially expressed in active progenitor cells but not in quiescent NSCs in the SGZ. This expression pattern of Ezh2 suggests that Ezh2 may regulate the process of adult neurogenesis, including aNSC proliferation, lineage commitment, and differentiation. It exhibited that Ezh2 decreased in differentiated progenies and then reappeared in mature neurons (Figs. 1D, Fig. 2E). Significantly, Ezh2 was detected in proliferating progenitor cells, indi- 

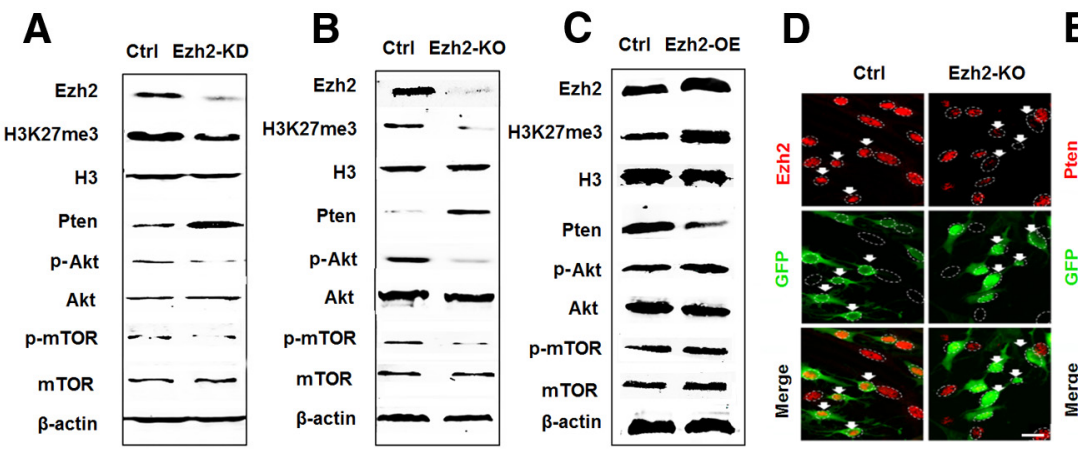

$\mathbf{E}$

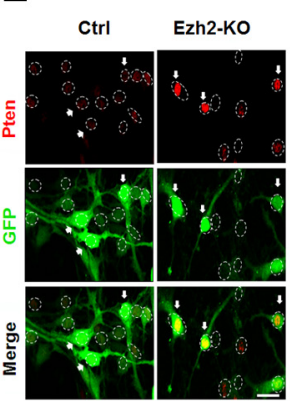

$\mathbf{F}$

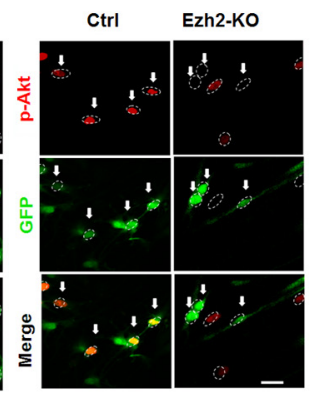

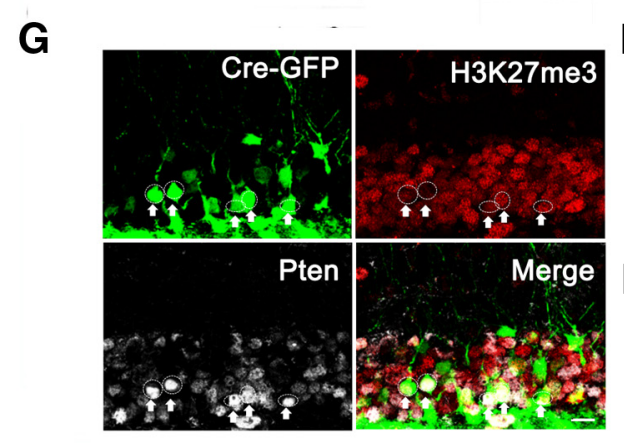

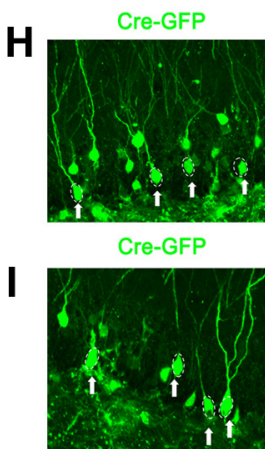

p-Akt

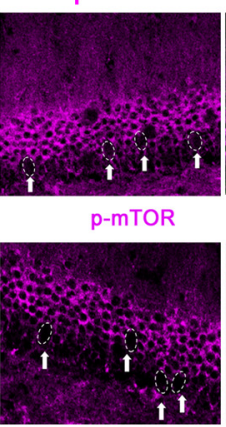

Merge

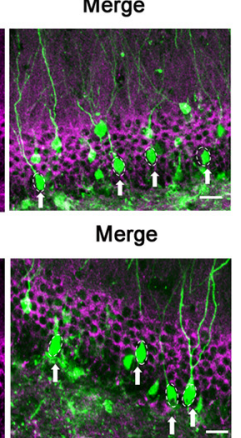

$\mathbf{J}$

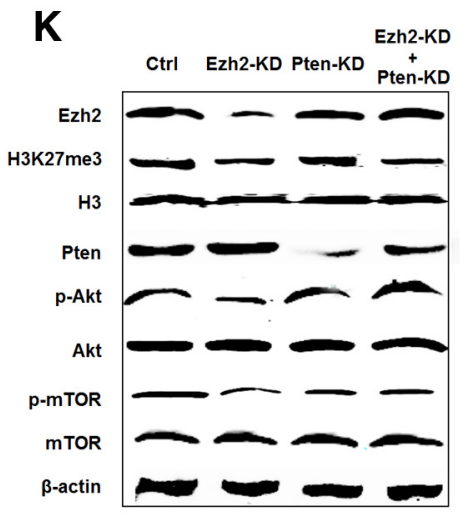

L
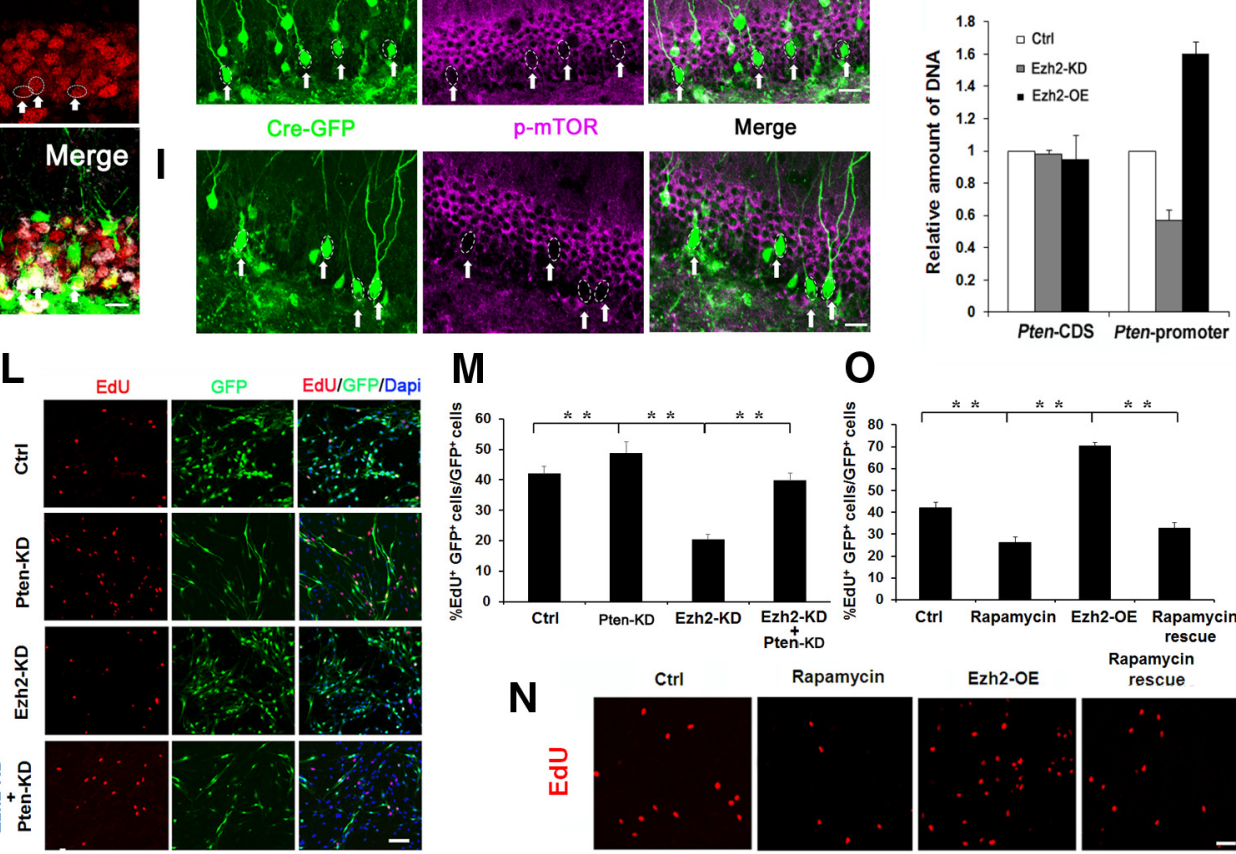

N
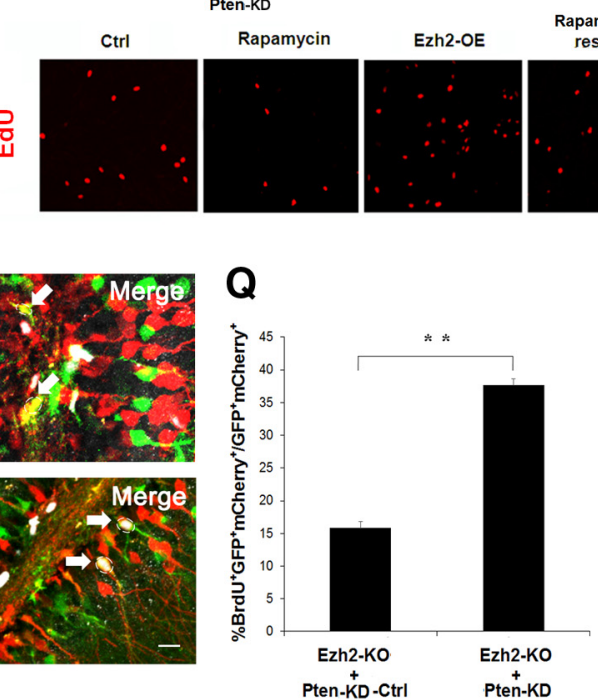

Figure 5. Ezh2 regulates progenitor cell proliferation through the Pten-Akt-mTOR signaling pathway. $A$, Ezh2 knockdown increased Pten levels and decreased the levels of $\mathrm{H} 3 \mathrm{~K} 27 \mathrm{me} 3, \mathrm{p}-\mathrm{Akt}$, and p-mTOR in primary NSCs/progenitor cells. Western blot analysis of the protein extracts from progenitor cells infected with control and Ezh2-shRNA retrovirus. B, Ezh2 deletion, mediated by Cre recombinase, increased the levels of Pten level and decreased the levels of $p$-Akt and p-mTOR. Western blot analysis of the protein extracts from progenitor cells infected with Cre retrovirus and the control. C, Western blotting showing the expression of Ezh2, H3K27me3, Pten, p-AKT, and p-mTOR in Ezh2 overexpressed primary NSCs/progenitor cells. D, Confocal images show that Ezh2 expression is rare detected in Cre retrovirus-infected progenitor cells. $\boldsymbol{E}$, Immun ofluorescent analysis showed activation of Pten in the Ezh2-deleted progenitor cells. Cells infected with retrovirus were stained with antibodies against Pten (red). Scale bar, $20 \mu \mathrm{m}$. F, Immunofluorescent analysis showed that p-Akt was suppressed in the Ezh2-deleted progenitor cells. Cells infected with retrovirus were stained with antibodies against p-Akt (red). Scale bar, $20 \mu \mathrm{m}$. G, Ezh2 loss leads to reduced H3K27me3 immunoreactivity and increased Pten expression in vivo. Concentrated retroviruses expressing Cre recombinase/GFP were injected stereotaxically into the DG of the Ezh2 $2^{f / f}$ mice. Brain sections were marked by antibody of H3K27me3 (red) and Pten (white). White arrowheads show $\mathrm{GFP}^{+} / \mathrm{H} 3 \mathrm{~K} 27^{-} /$Pten ${ }^{+}$cells. $\mathrm{H}$, Ezh2 ablation results in decreased p-AKT immunoreactivity in the DG of adult hippocampus. White arrowheads show GFP ${ }^{+} / \mathrm{p}-\mathrm{AKT}{ }^{-}$cells. I, Ezh2 deletion leads to reduced p-mTOR immunoreactivity in the DG of adult hippocampus. White arrowheads show GFP ${ }^{+} / \mathrm{p}-\mathrm{mTOR}^{-}$cells. J, ChIP analysis showed that Ezh2 inhibited Pten expression by promoting H3K27 methylation on the Pten promoter. Cells infected control, Ezh2 shRNA, and Ezh2 overexpression retrovirus were harvested and sonicated. DNA fragments were quantified using real-time PCR with primers for the Pten promoter and for the Pten coding sequences. $\boldsymbol{K}$, Western blot analysis showing that Pten knockdown can rescue the expression of $p$-AKT (Figure legand continues.) 
cating a potential role of Ezh2 in regulating the proliferation of progenitor cells.

\section{Ezh2 regulates the proliferation of progenitor cells in vitro}

Given the expression of Ezh2 in progenitor cells, we then explored the direct roles of Ezh2 in progenitor cell proliferation and differentiation by infecting primary NSCs/progenitor cells with recombinant retroviruses expressing Ezh2 or Ezh2-shRNA. Western blot analysis confirmed that the expression of Ezh2 was significantly higher in the retrovirus-Ezh2-overexpressioninfected group compared with the control. Meanwhile, Ezh2 expression was significantly lower in the progenitor cells infected with the retrovirus-Ezh2-shRNA than in the controls (Fig. 3A). Using these viruses, we performed proliferation and differentiation assays in vitro. Adult progenitor cells infected with retrovirus-Ezh2-overexpreesion showed increased proliferation, whereas progenitor cells infected with retrovirus-Ezh2-shRNA showed reduced proliferation (Fig. $3 B, C$ ). Consistent with the above findings, Ezh2 overexpression increased the cell cycle entry of progenitor cells $\left(\mathrm{Ki}_{67}{ }^{+}\right.$), whereas Ezh2 knockdown decreased the cell cycle entry of progenitor cells. Of note, there was no significant difference in the levels of apoptosis between the groups, demonstrating that cell death was not a major consequence of Ezh2 overexpression or knockdown (data not shown). Moreover, the function of Ezh2 in progenitor cell proliferation was further confirmed using the neurosphere assay. Adult progenitor cells infected with retrovirus-Ezh2-overexpression formed larger neurospheres than the control cells, whereas Ezh2depleted progenitor cells formed smaller neurospheres (Fig. $3 D, E)$. The in vitro data suggest that Ezh2 knockdown decreases progenitor cell proliferation.

To further confirm the role of Ezh2 in adult progenitor cell proliferation, NSCs/ progenitor cells isolated from Ezh $2^{\mathrm{f} / \mathrm{f}}$ mice were infected with a retrovirus that expressed Cre recombinase. Ezh2 was deleted in the retrovirus Cre-infected progenitor cells, as shown by Western blot analysis (Fig. $3 F$ ). Consistent with the knockdown results, the inactivation of Ezh2 reduced the proliferation of the adult progenitor cells (Fig. 3G,H). Moreover, there was significant difference in the proportion of cells in the $G_{0} / G_{1}$ phase between the retrovirus Cre-infected adult progenitor cells and the control cells (Fig. 3I,J), indicating that the deletion of Ezh2 led to decreased adult progenitor cell proliferation. Thus, Ezh2 may promote the entry of progenitor cells into the cell cycle, leading to the amplification of the progenitor cells.

\section{Ezh2 alters the proliferation of progenitor cells in vivo}

To examine the role of Ezh2 in progenitor cells in vivo, Ezh2 $2^{-/-}$ mice were generated by breeding Nestin-Cre mice with Ezh2 fff

\footnotetext{
(Figure legand continued.) and p-mTOR when Ezh2 was knocked down. $L$, Knockdown of Pten using a lentivirus expressing Pten siRNA rescued the decrease in progenitor cell proliferation that resulted from Ezh2 knockdown. Progenitor cells were infected with control or Ezh2-shRNA retrovirus or were coinfected with Pten-shRNA lentivirus and Ezh2-shRNA retrovirus. The proliferating cells were labeled with EdU (red). Scale bar, $20 \mu \mathrm{m}$. M, Quantitative analysis of the EdU-labeled cells. $\boldsymbol{N}$, Rapamycin treatment rescued the increased proliferation caused by Ezh2 overexpression. Progenitor cells were infected with Ezh2 overexpression retrovirus and then treated with $0.3 \mathrm{~nm}$ rapamycin. The proliferating cells were traced with EdU (red). Scale bar, 100 $\mu \mathrm{m} . \mathbf{0}$, Quantitative analysis of the EdU-labeled cells. $\boldsymbol{P}$, Pten knockdown mediated by lentivirus infection can rescue the decrease of progenitor cell proliferation caused by Ezh2 deletion. Viruses that express Cre recombinase/GFP or pten-KD/mCherry were mixed and injected stereotaxically into the DG of Ezh2 $2^{f / f}$ mice. Proliferated cells were labeled by BrdU injection. $\mathbf{Q}$, Percentage of BrdU-positive cells in GFP and mCherry colabeled cells. Value represents mean \pm SEM. Student's $t$ test; ${ }^{*} p<0.05,{ }^{* *} p<0.01$.
}

mice. Although Ezh2 ff;Nestin-Cre mice were similar to their littermate controls in outward appearance, these mice showed progressive growth retardation and usually died at P15-P20. Therefore, experiments using the Ezh2 f/fiNestin-Cre mice and control mice were performed at approximately P20. As expected, Ezh2 was totally ablated in the brains of these mice. Simultaneously, brains from $E z h 2^{f / f ; N e s t i n-C r e}$ mice were significantly lighter than brains of the littermate controls (data not shown). Consistent with this result, fewer and smaller neurospheres were formed

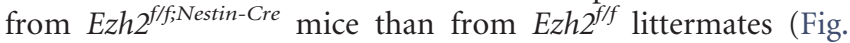
$4 A, B)$, indicating that Ezh2 is an essential regulator of progenitor cell proliferation in vivo.

Because the survival of Ezh2ff;Nestin-Cre homozygous knock-

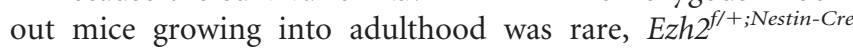
heterozygous mice were used for further analysis of the proliferation defects revealed by the reduction in neurosphere size. As expected, the expression of Ezh2 was reduced, but the survival of the Ezh $2^{f /+ \text {;Nestin-Cre }}$ mice was not affected. Similarly, brains isolated from the Ezh $2^{f /+; N e s t i n-C r e}$ mice were also lighter than those from the controls. The neurospheres formed from Ezh2 $2^{f /+; N e s t i n-C r e}$ mice were also fewer and smaller than those from controls (Fig. $4 C, D)$. Using the BrdU tracing approach, as shown in Figure $4 E$, we counted the BrdU-positive cells in the DG. Compared with $E z h 2^{f / f}$ mice, BrdU incorporation was significantly decreased in Ezh $2^{f /+; N e s t i n-C r e}$ mice, indicating that the reduction in Ezh2 expression suppressed the proliferation of progenitor cells (Fig. $4 E, F)$. Together, these results indicate that Ezh2 is an important regulator of progenitor cell proliferation, and loss of Ezh2 may impair the amplification of progenitor cells.

Because Ezh2 is specifically and constitutively deleted in Ezh $2^{f /+ \text {;Nestin-Cre }}$ (icKO) mice, it is difficult to distinguish whether Ezh2 plays roles in the adult or in the embryo. To further address this question, conditional deletion mice were produced by crossing Nestin-CreERT2 mice with Ezh2 $2^{f / f}$ mice. The 5-week-old Ezh2 ff; Nestin-CreERT2 mice were administered tamoxifen for 5 consecutive days and injected with BrdU $5 \mathrm{~d}$ later. The number of BrdU-positive cells was significantly reduced in the Ezh2 icKO mice (Fig. 4G,H; 3-fold decrease compared with tamoxifen-treated control). In support of these findings, NSCs/progenitors from adult Ezh2 icKO mice formed primary and secondary neurospheres at a significantly lower frequency and with a smaller size than those from the littermate controls, suggesting Ezh2 plays an essential role in progenitor cell proliferation (Fig. $4 I, J$ ).

To directly investigate the role of Ezh2 in proliferation, recombinant retroviruses expressing Cre recombinase were stereotaxically injected into the right DG of Ezh f/f mice. Because retroviruses only infect dividing cells, we can specifically ablate the expression of Ezh2 in the dividing cells. BrdU tracing was performed $5 \mathrm{~d}$ after retrovirus injection. Consistent with the icKO mice, BrdU-labeled cells were significantly decreased compared with controls (Fig. $4 K, L$ ), indicating the important role of Ezh2 in the proliferation of progenitor cells.

\section{Ezh2 regulates adult neurogenesis by targeting the Pten-Akt- mTOR signaling pathway}

The above-mentioned results suggest that Ezh2 is important for progenitor proliferation. To shed light on its mechanism of action, we examined the impact of Ezh2 on several canonical proliferation pathways. As Ezh2 can trimethylate lysine 27 of histone $\mathrm{H} 3$ and lead to the silence of target genes, we first detected the levels of H3K27me3 by Western blot analysis. As expected, the level of H3K27me3 was upregulated when Ezh2 was overex- 
A

\begin{tabular}{|c|c|c|c|}
\multicolumn{1}{c}{ TAM } & \multicolumn{1}{c}{ BrdU } & & Perfusion \\
Injection (i.p.) & Injection (i.p.) & & 1 Day
\end{tabular}
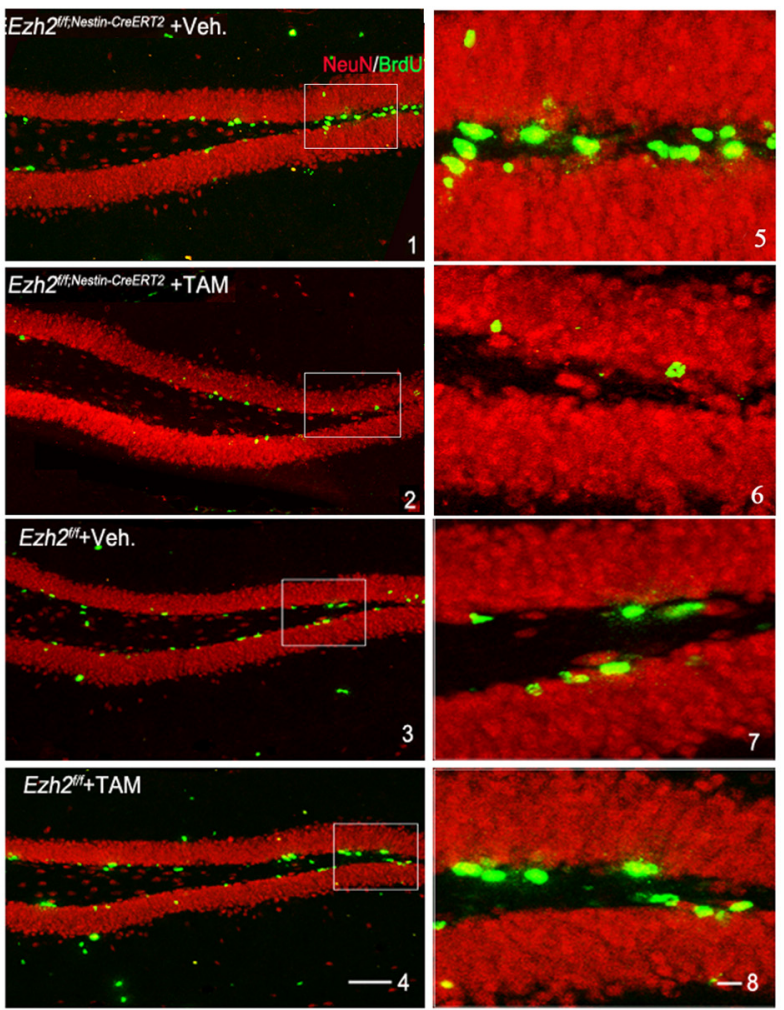

$\mathbf{E}$

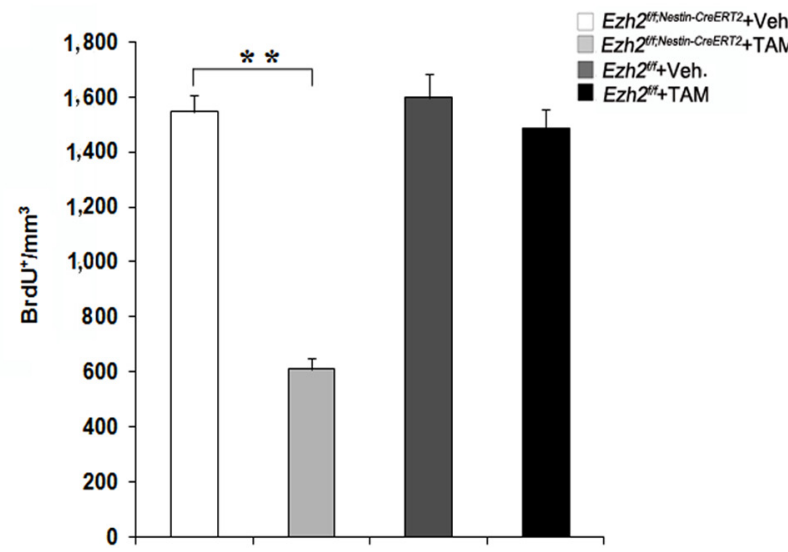

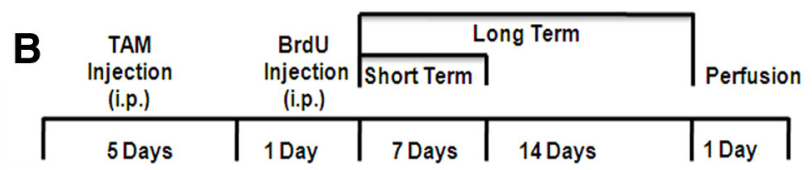
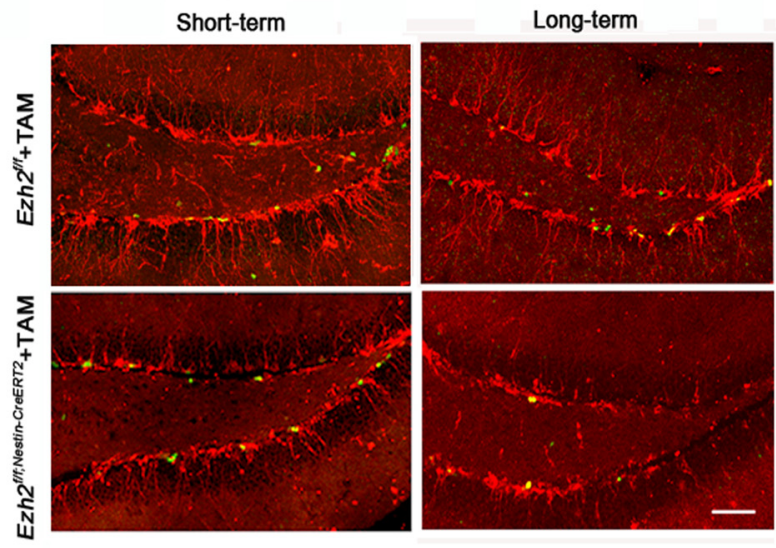

C

Short-term
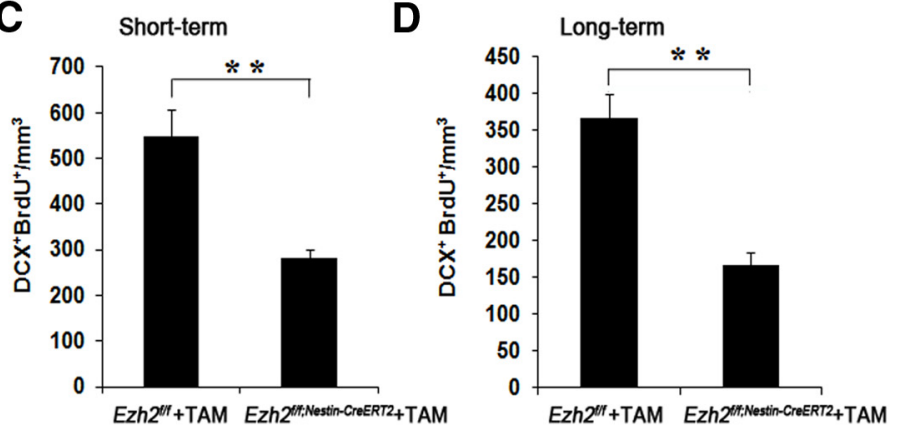

$\mathbf{F}$

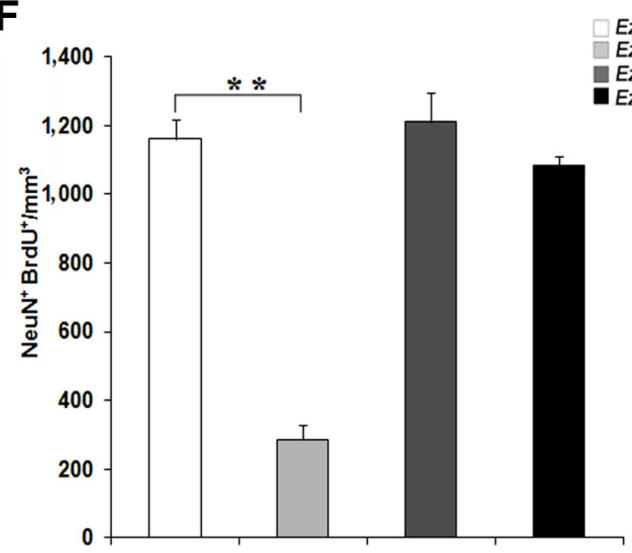

Figure 6. Loss of Ezh2 results in a decrease in neurogenesis in the SGZ. A, Representative sections of the DG stained with the mature neuron marker NeuN (red) and the proliferation marker BrdU (green) 3 weeks after $5 \mathrm{~d}$ of tamoxifen or vehicle treatment. $5-8$, Enlarged images taken from boxed regions in 1-4. Scale bar, $100 \mu \mathrm{m}$. $\boldsymbol{B}$, Number of newly born neurons decreased after the inducible deletion of Ezh 2 in both short-and long-term experiments. BrdU was injected on the fifth day after tamoxifen treatment. Mice were killed either 1 week later (short term) or 3 weeks later (long term). Representative sections of the DG were stained with the immature neuron marker DCX (red) and the proliferation marker BrdU (green). Scale bar, $100 \mu \mathrm{m}$. C, Quantification of the $\mathrm{DCX}^{+} / \mathrm{BrdU}{ }^{+}$cells in the short-term period following Ezh2 deletion. $\boldsymbol{D}$, Quantification of the $\mathrm{DCX}{ }^{+} / \mathrm{BrdU}{ }^{+}$cells in the long-term period following Ezh2 deletion. $\boldsymbol{E}$, The number of surviving BrdU-positive cells decreased in the adult hippocampus 3 weeks after the inducible deletion of Ezh2. The number of BrdU-labeled cells was normalized to the volume of the DG. $\boldsymbol{F}$, Quantitative analysis of the reduced number of new neurons (BrdU and NeuN double-labeled cells) observed in $\boldsymbol{B}$. Value represent mean $\pm \mathrm{SEM}$. Student's $t$ test; ${ }^{*} p<0.05{ }^{* * *} p<0.01$.

pressed, whereas the level of $\mathrm{H} 3 \mathrm{~K} 27 \mathrm{me} 3$ was downregulated when Ezh2 was knocked down (Fig. 5A,C). These results demonstrate that Ezh2 works as an epigenetic regulator. Further analysis showed that Pten (phosphatase and tensin homolog) was downregulated by Ezh2. Knockdown of Ezh2 in the progenitor cells led to Pten expression increase, whereas overexpression of Ezh2 led to a reduction in Pten expression. Simultaneously,
p-Akt and p-mTOR were decreased in the Ezh2 knockdown group and increased in Ezh2 overexpressed group, indicating that Ezh2 is involved in the Akt-mTOR signaling pathway by suppressing Pten (Fig. $5 A, C$ ).

To further verify that Ezh2 affects the Akt/mTOR signaling pathway, progenitor cells isolated from $E z h 2^{f / f}$ mice were infected with retrovirus expressing Cre recombinase to ablate the expres- 


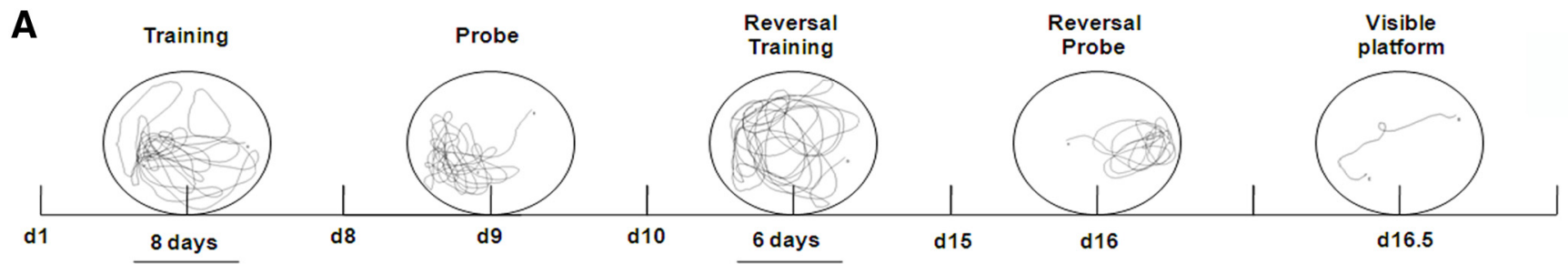

B

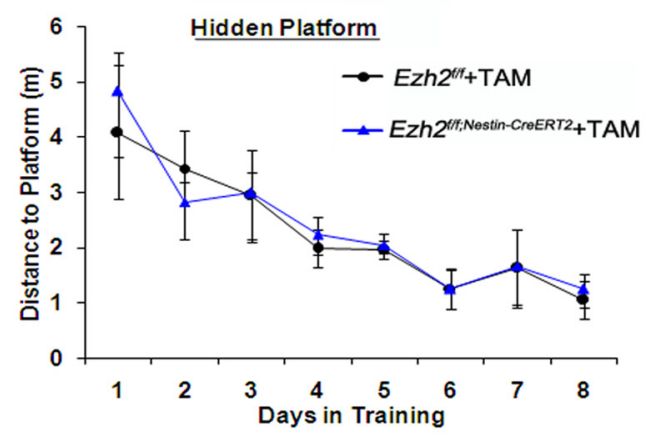

D

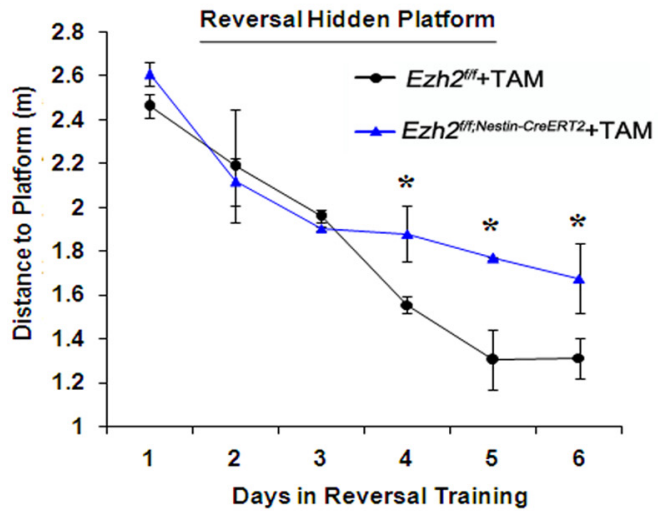

$\mathbf{F}$

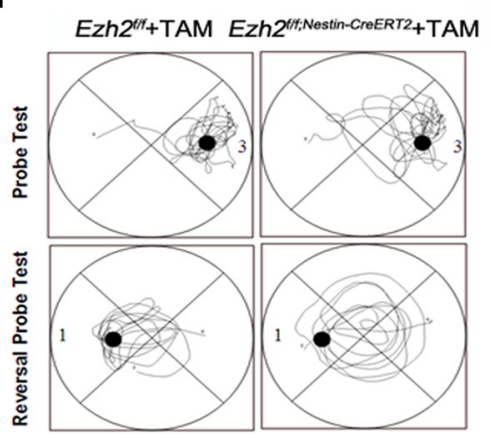

G

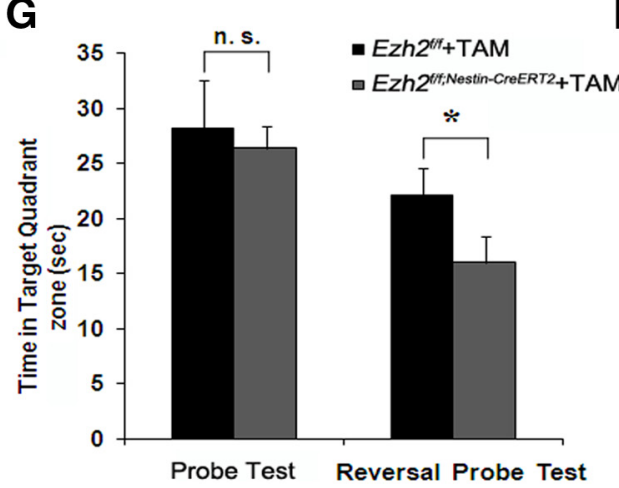

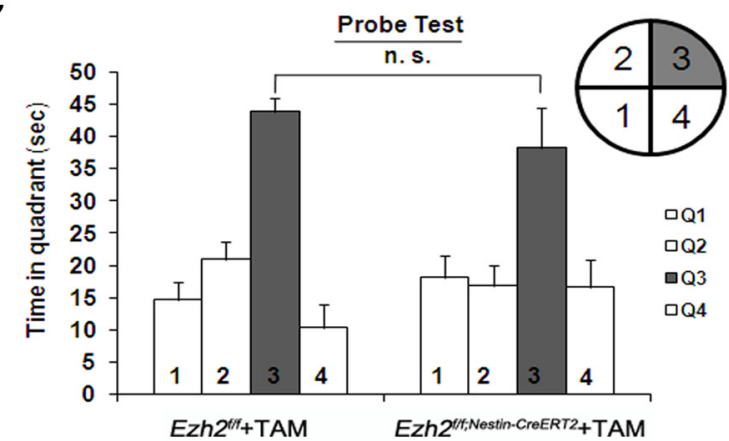

E

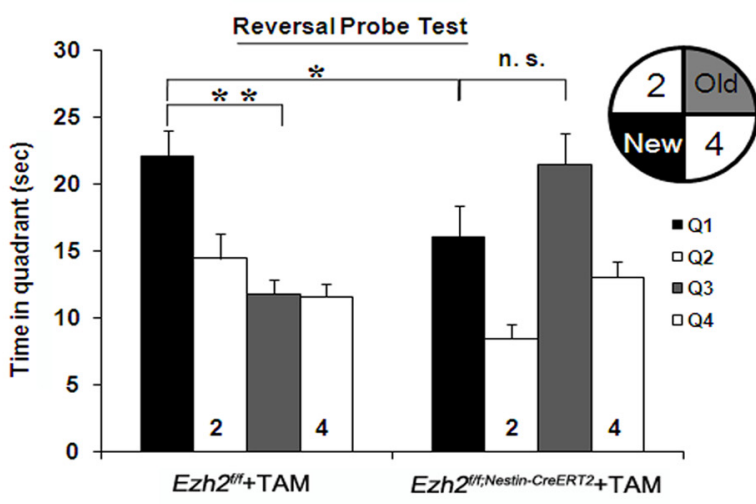

- Ezh2 $2^{f i t}+$ TAM

- Ezh2 $2^{\text {ffiNestin-CreERT2 }}+$ TAM

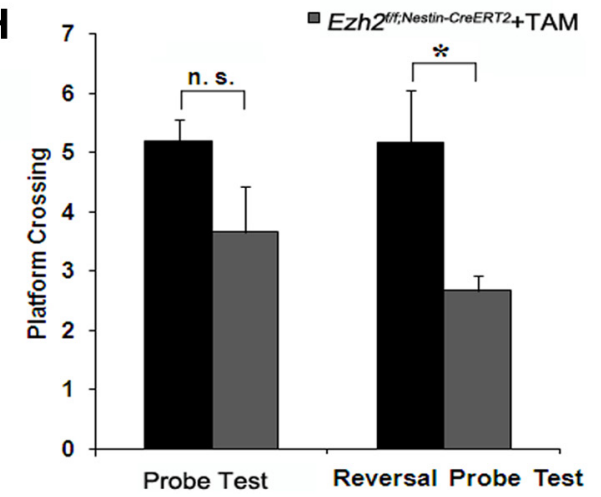

Figure 7. Deletion of Ezh2 from NSCs results in impaired spatial learning and memory. $A$, Schematic illustration of the experimental design. Mice were trained for $8 \mathrm{~d}$ in the Morris water maze and tested $24 \mathrm{~h}$ later. They were then subjected to $6 \mathrm{~d}$ of reversal training by transferring the hidden platform to the opposite quadrant of the water maze. Reversal probe test was performed $24 \mathrm{~h}$ later, followed by a visible platform test. $\boldsymbol{B}$, Swim distance to the platform decreased during the training process, and there was no significant difference between Ezh2 icKO mice and control mice, indicating a similar spatial learning ability. C, Ezh2 icK0 mice spent a similar amount of time in the target quadrant as the control mice in the probe test. $\boldsymbol{D}$, Ezh2 icK0 mice swam longer distances than the control mice after $4 \mathrm{~d}$ of reversal training, indicating that they suffered from impaired learning of new spatial learning. $\boldsymbol{E}$, Ezh2 ick0 mice spent less time in the target quadrant than control mice during the reversal probe test. In contrast, control mice spent more time in the new target quadrant than in the old one. $\boldsymbol{F}$, Representative tracing pathway of control and Ezh2 $\mathrm{icKO}$ mice in the probe test and the reversal probe test. G, Ezh2 icK0 mice also spent less time in the area of the target platform after the hidden platform was removed in the reversal probe test. $\boldsymbol{H}$, Crossing times of Ezh2 icKO mice were fewer than control mice in the reversal probe test. Value represents mean $\pm \mathbf{S E M}$. One-way ANOVA; ${ }^{*} p<0.05,{ }^{* *} p<0.01$. 
A

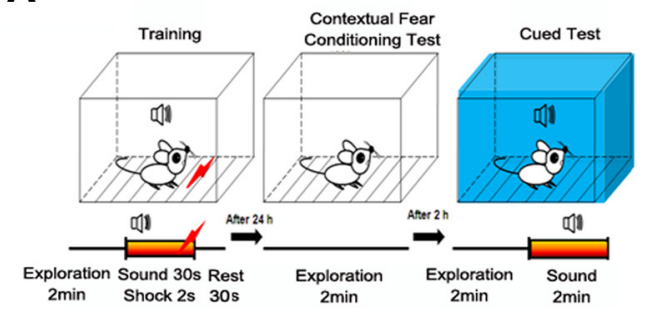

B

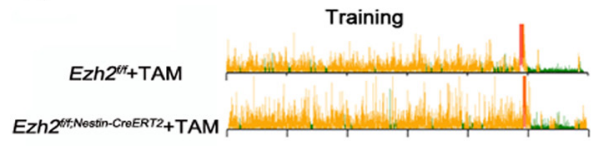

Contextual test

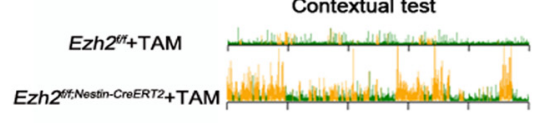

Cued test
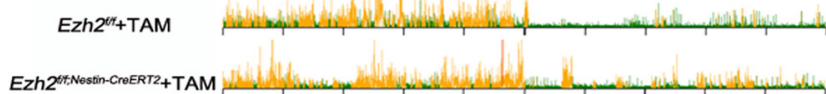

C
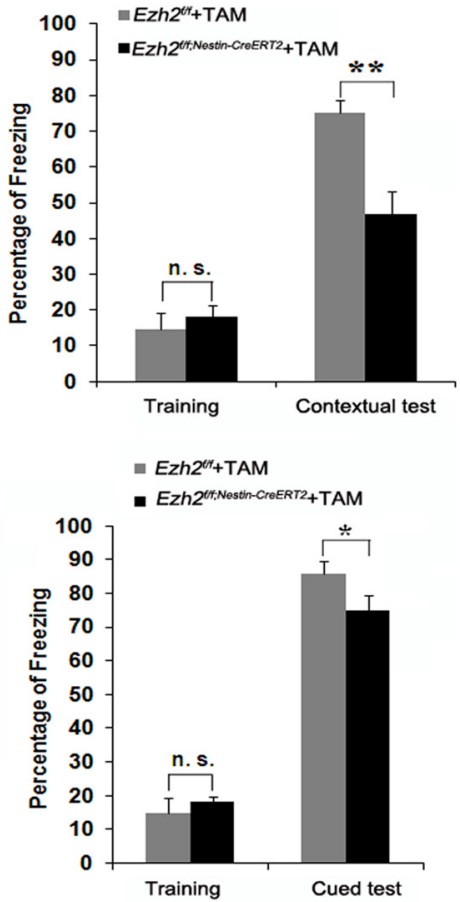

E

Training and testing

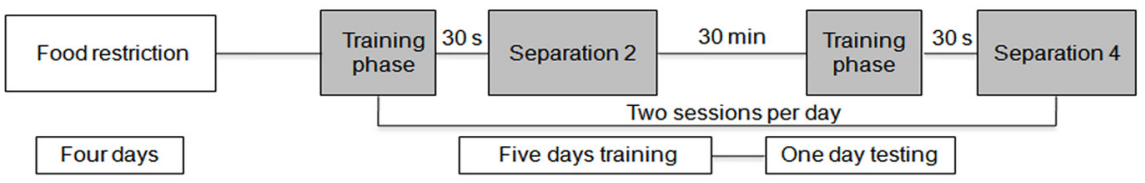

$\mathbf{F}$

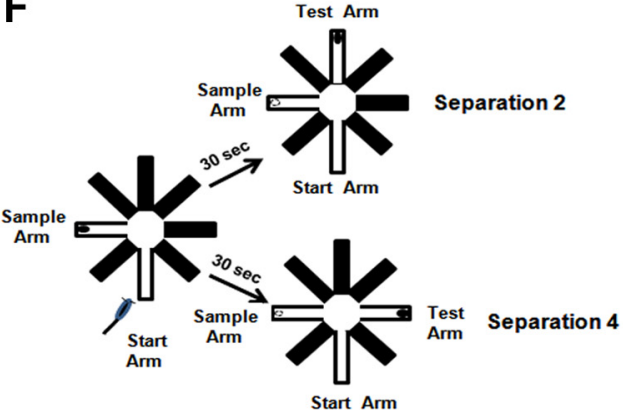

Training phase

Choice phase
G

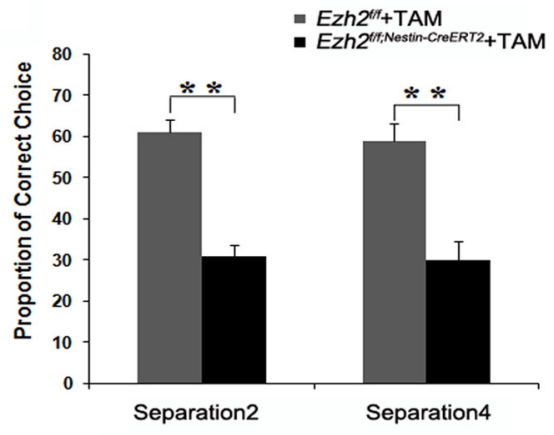

H
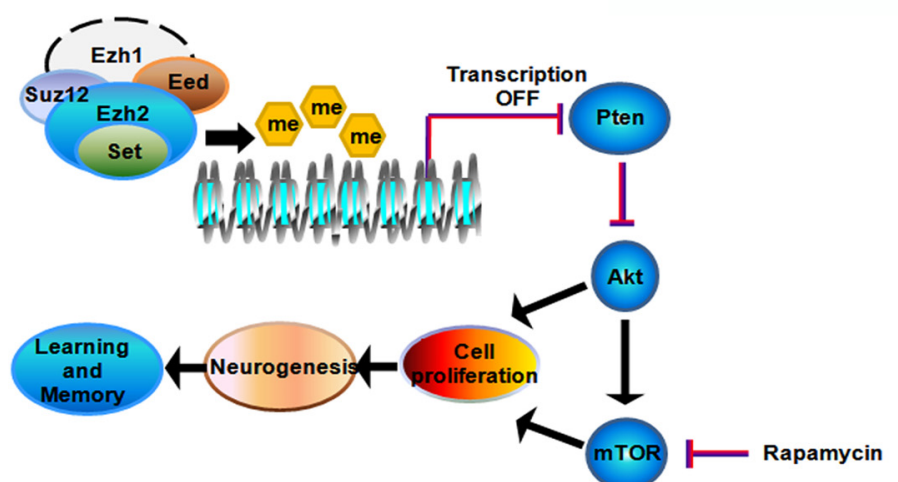

Figure 8. Ablation of Ezh2 leads to impairments in contextual fear memory and deficits in pattern separation. A, Schematicillustration of the experiment designed for fear conditioning. Ezh2 ick0 mice and their littermate controls were subjected to $30 \mathrm{~s}$ of sound and a $2 \mathrm{~s}$ of footshock with $0.7 \mathrm{~mA}$ current. Contextual fear-conditioning test was performed $24 \mathrm{~h}$ later, followed by a cued test $2 \mathrm{~h}$ later. B, Behavioral distributions of Ezh2 icK0 mice and controls during training and testing. C, Percentage of freezing in Ezh2 ick0 mice was less than in littermate controls (Figure legand continues.) 
sion of Ezh2. Similarly, the loss of Ezh2 resulted in the upregulation of Pten and the downregulation of p-Akt and p-mTOR (Fig. $5 B)$. Moreover, immunostaining results showed an increase in Pten expression and a decrease in p-AKT in the Ezh2 ablated cells (Fig. 5D-F). Meanwhile, RT-PCR results further supported this conclusion (data not shown). To detect the effect of Ezh2 on Pten-AKT-mTOR signaling pathway in vivo, H3K27me3, Pten, $\mathrm{p}$-AKT, and p-mTOR staining were performed in brain sections of retrovirus Cre-infected Ezh2 $2^{f / f}$ mice. Consistently, H3K27me3 immunoreactivity was reduced, whereas the expression of Pten was increased after Ezh2 was deleted (Fig. 5G). Similarly, the immunoreactivity of p-AKT and p-mTOR was also reduced in retrovirus-infected cells (Fig. $5 \mathrm{H}, \mathrm{I}$ ). Importantly, ChIP assays showed that Ezh2 inhibited Pten expression by promoting H3K27 methylation at the promoter of the Pten gene (Fig. 5J), whereas promoters of the Dlx2 and $P 21$ genes, which are required for neurogenesis and cell cycle progression, were not altered (data not shown). Therefore, our results further confirmed the role of Ezh2 in the Akt-mTOR signaling pathway.

To test whether Ezh2 regulates progenitor proliferation through the Akt-mTOR signaling pathway, primary progenitor cells were coinfected with recombinant lentivirus expressing Pten-shRNA and retrovirus expressing Ezh2-shRNA. Western blot analysis showed that Pten knockdown can rescue the levels of p-AKT and p-mTOR when Ezh2 was knocked down (Fig. 5K). Proliferation capability of the cells was analyzed by EdU labeling. As expected, the rate of EdU incorporation in the Pten and Ezh2 double knockdown progenitor cells was similar to control cells and was significantly higher than in the Ezh2 knockdown progenitors (Fig. $5 L, M$ ). These results indicated that Pten knockdown could completely rescue the reduced proliferation caused by Ezh2 knockdown. To investigate whether Ezh2 regulates progenitor cell proliferation through the downstream target, p-mTOR, primary NSCs/progenitor cells were infected with retrovirus-Ezh2-overexpression and then treated with rapamycin, an inhibitor of mTOR. Importantly, the inhibition of p-mTOR significantly decreased the number of EdU-positive cells in the Ezh2-overexpressing progenitor cells, suggesting that the inhibition of mTOR was able to rescue the increased proliferation caused by Ezh2-overexpression (Fig. 5N,O). To detect the rescue efficiency of Pten knockdown, viruses that express Cre recombinase/GFP or Pten-shRNA/mCherry were mixed and injected stereotaxically into the DG of Ezh $2^{f f f}$ mice. BrdU-positive cells were quantified in GFP and mCherry colabeled cells. Compared with control, the percentage of proliferating cells was significantly increased in Cre and Pten-shRNA coexpressing progenitor cells (Fig. 5P,Q).Together, these results suggest that Ezh2 regulates progenitor cell proliferation through the PtenAkt-mTOR signaling pathway.

\section{Conditional deletion of Ezh2 inhibits neurogenesis in adult mice}

Whether the deficient progenitor cell proliferation caused by Ezh2 deletion impaired the neurogenesis in the adult hippocam-

\section{$\leftarrow$}

(Figure legand continued.) when exploring the same background. D, Freezing response was reduced in the Ezh2 icK0 mice compared with the controls in the tone-cued test. $\boldsymbol{E}$, Timeline for the radial arm maze pattern separation assay. Mice were dieted for $4 \mathrm{~d}$ and then trained for $5 \mathrm{~d}$. The test was performed $24 \mathrm{~h}$ later. $\boldsymbol{F}$, Schematic illustration of the experimental design. $\boldsymbol{G}$, Ezh2 ick0 mice made fewer correct choices in both separation 2 and separation 4. H, Model for Ezh2's role in regulating adult neurogenesis and cognitive function. Value represents mean \pm SEM. One-way ANOVA; ${ }^{*} p<0.05,{ }^{* *} p<0.01$. pus is unknown. To test this possibility, the mice were analyzed 3 weeks after the last BrdU injection to detect the long-term effect of Ezh2 deletion in adult neurogenesis. We found a marked reduction in the number of BrdU-positive cells in the Ezh2 icKO mice. However, there were no significant differences between $E z h 2^{f f f}$ mice treated with tamoxifen and those treated with vehicle in the number of BrdU-positive cells. These results suggest that Ezh2 deletion has a long-term effect on neurogenesis (Fig. 6A,E). Simultaneously, we also observed a significant decrease in the number of NeuN and BrdU double-labeled cells in the Ezh2 icKO mice (Fig. $6 A, F$ ), indicating that the loss of Ezh2 also had a longterm effect on neuronal differentiation. Moreover, the immature neurons labeled with DCX were also reduced in both the short- and long-term tracing in the Ezh2 icKO mice (Fig. $6 B-$ $D)$, suggesting the deficiency of progenitor cell proliferation also impaired the production of new neurons. Together, these results indicate that Ezh2 is essential for progenitor cell proliferation and neuronal differentiation in adult brains.

\section{Conditional deletion of $E z h 2$ impairs spatial learning and memory}

The important function of the hippocampus in learning and memory is well known (Zhang et al., 2008a; Guo et al., 2011). To test whether the loss of Ezh2 affects spatial learning and memory, adult Ezh2 $2^{\mathrm{f} f \text {;Nestin-CreERTM } 2}$ mice, as well as their littermate controls, were examined by the Morris water maze experiment 4 weeks after $5 \mathrm{~d}$ of consecutive tamoxifen treatment (Fig. 7A). There was no significant difference in the swim distance between the Ezh2 icKO mice and the controls during the eight training days (Fig. $7 B$ ). There was also no significant difference in the probe trial $24 \mathrm{~h}$ after the training (Fig. $7 C$; one-way ANOVA, $\left.F_{(1,14)}=0.291, p=0.598\right)$.

To further explore whether spatial learning and memory are affected by Ezh2 in a more complex condition, reversal training was performed by moving the hidden platform to the opposite quadrant. In this experiment, the mice must forget the old location of the hidden platform and learn to search for it in a new location. Interestingly, the Ezh2 icKO mice showed significant delays in learning after the third day of reversal training (Fig. 7D), indicating their inability to associate a previous experience with a new location. The reversal probe test was performed $24 \mathrm{~h}$ after the last training. As expected, the Ezh2 icKO mice spent less time in the target quadrant than the control mice. Moreover, the Ezh2 icKO mice spent more time in the old target quadrant than in the new one, whereas the control group showed an opposite result (Fig. 7E). In line with these data, both the time spent in the target platform zone (Fig. $7 G ; F_{(1,14)}=5.327, p=0.041$ ) and the times of platform crossing (Fig. $7 H ; F_{(1,14)}=6.215, p=0.032$ ) were significantly decreased in the Ezh2 icKO group compared with the control when the hidden platform was removed in the reversal probe test. The following visible platform test showed that the impairments of the Ezh2 icKO mice in spatial learning and memory were not due to the differences in swim speed or visual ability (data not shown). These data suggest that Ezh2 is highly correlated with reversal learning and memory.

\section{Inducible deletion of Ezh2 affects contextual fear memory}

Previous studies have shown that adult hippocampal neurogenesis may also be involved in contextual fear conditioning (Saxe et al., 2006; Winocur et al., 2006). To test whether the Ezh2 icKO mice were deficient in contextual fear stimulation, a cohort of mice, 4 weeks after tamoxifen injection, was trained according to the following process: exploration for $2 \mathrm{~min}$, sound presentation 
for $30 \mathrm{~s}$, shocking for the last $2 \mathrm{~s}$ of the sound presentation, and rest for $30 \mathrm{~s}$ (Fig. 8A). Interestingly, the freezing percentage of the Ezh2 icKO mice was significantly decreased compared with the control mice in the contextual test, indicating that the deletion of Ezh2 impaired the formation of contextual memory caused by background (Fig. $8 B, C ; F_{(1,18)}=8.213, p=0.01$ ). The tone-cued memory test showed that the freezing time of the Ezh2 icKO mice was also decreased compared with the control mice, suggesting that the contextual memory caused by the tone was also ablated in the Ezh2 icKO mice (Fig. $8 B, D ; F_{(1,18)}=5.097, p=0.038$ ). Furthermore, the open-field test showed that the Ezh2 icKO mice had no defects in vision or mobility. Collectively, these results showed that the deletion of Ezh2 affects the formation of contextual memory generated by the background or the tone.

\section{Ezh2 icKO mice are deficient in pattern separation}

Pattern separation is a difficult form of spatial learning and memory that has been associated with the SGZ (Guo et al., 2011). To illustrate the effect of Ezh2 on pattern separation, the Ezh2 icKO mice and their littermate controls were subjected to the radial arm maze pattern separation experiment (Fig. $8 E, F$ ). The frequency of the Ezh2 icKO mice that found the correct arm was less than the control mice in both separations 2 and 4 (Fig. $8 G ; F_{(1,20)}=17.922$, $p<0.001$ in separation 2 and $F_{(1,20)}=12.670, p=0.002$ in separation 4). These data showed that the Ezh2 icKO mice have a deficit in pattern separation.

\section{Discussion}

NSCs are a class of cells that is capable of self-renewal and can give rise to various neural lineages, such as neurons, astrocytes, and oligodendrocytes. The progression from NSCs to functional neurons is known as neurogenesis, and this process involves the proliferation of the NSCs/progenitor cells, their differentiation into neurons, and the integration of the new neurons into the existing neural circuitry. In the adult brain, neurogenesis is thought to play an important role in maintaining cognitive functions, such as learning, memory, and spatial pattern separation. Epigenetic regulations have been shown to be crucial for NSC maintenance and differentiation. For example, loss of MBD1 leads to a reduction in adult neurogenesis and impaired spatial learning (Zhao et al., 2003). Additionally, PcG-mediated histone modification and DNA methylation have critical roles in maintaining NSCs. However, as an important component of the PcG complex, the role of Ezh2 in adult neurogenesis is largely unknown.

Here, we are the first to report the crucial function of Ezh2 in adult neurogenesis, learning, and memory. Our results showed that Ezh2 is expressed in active progenitor cells but not in quiescent NSCs. The role of Ezh2 in the regulation of progenitor proliferation was detected both in vitro and in vivo. In the absence of Ezh2, progenitor cells showed an impaired capability to proliferate and give rise to new neurons. Our findings also revealed that Ezh2 regulates progenitor cell proliferation by regulating the Pten-Akt-mTOR signaling pathway. Ezh2 icKO ultimately resulted in impaired spatial learning and memory, contextual fear memory, and pattern separation (Fig. $8 H$ ). Together, these data indicate that Ezh2 is an important regulator of progenitor proliferation and neurogenesis.

Our studies may shed light on the mechanism behind the Ezh2 regulation in progenitor proliferation. As an important epigenetic regulator, Ezh2 can trimethylate lysine 27 of histone H3, leading to the silencing of specific target genes. One target gene, Pten, negatively regulates NSC proliferation in adult neurogenesis. Conditional deletion of Pten in adult NSCs in the sub- ependymal zone can enhance the self-renewal ability of NSCs and leads to constitutive neurogenesis in the olfactory bulb (Gregorian et al., 2009). Another study showed that Pten deletion in adult NSCs in the SGZ results in increased proliferation (Amiri et al., 2012). Similarly, we found decreased BrdU-labeled or EdUlabeled cells when Ezh2 was knocked down or knocked out in vivo or in vitro. Pten deletion in granule neurons resulted in increased soma, apical dendrites, and spine density (Bonaguidi et al., 2011; Pun et al., 2012). In our study, no obvious aberrant newborn neuron morphology was observed in Ezh2 deleted granule neurons. Perhaps, the upregulation of Pten caused by Ezh2 deletion has no obvious effect on newborn neuron development. A previous report showed that Ezh2 is required for Pten downregulation in hematopoietic stem cells (Yoshimi et al., 2011). The deletion of Pten in hematopoietic stem cells leads to their short-term expansion but results in their depletion in the long term (Yilmaz et al., 2006). Our results further demonstrated that Ezh2 also promoted the expansion of progenitor cells by suppressing Pten and increasing Akt-mTOR signaling.

Both in vitro and in vivo data consistently support the hypothesis that Ezh2 deletion decreased progenitor proliferation. Whether inactivation of Ezh2 leads to aberrant differentiation of NSCs is unknown. In vitro, Ezh2 was reported to promote neuronal differentiation in embryonic NSCs (Sher et al., 2008). However, a significant decrease in the number of neurons labeled by BrdU in the Ezh2 icKO mice was observed in our study, indicating the deficient progenitor proliferation caused by Ezh 2 deletion impaired the neurogenesis in the adult hippocampus. Such results may be caused by the differences in the number of original progenitor cells and the different survival conditions. In vitro, the same initial number of progenitor cells was plated and cultured in differentiation medium to investigate the role of Ezh2 in NSC differentiation. However, the deletion of Ezh2 in vivo resulted in a significantly reduced number of progenitors. Therefore, the reduction in neuron production in vivo was mainly caused by the decreased number of NSCs. Meanwhile, the differences in growth conditions in vivo and in vitro may also lead to divergence in neuron production. In fact, lineage-restricted neural progenitor cells may alter their properties after stimulation with growth factors in vitro (Stiles, 2003); therefore, there may be a slight difference between these two conditions.

Progenitor proliferation and neurogenesis defects associated with Ezh2 deletion may contribute to a fraction of the symptoms of Weaver's syndrome, which has been correlated with an Ezh2 mutant. Characteristics of Weaver's syndrome include brain abnormalities and learning/memory disabilities (Cohen, 2003). In our study, Ezh2-null NSCs/progenitors could not efficiently proliferate or differentiate into neurons, leading to memory defects and providing a possible molecular and cellular mechanism of Weaver's syndrome.

Furthermore, Ezh2-null mice exhibited impaired spatial learning and memory, contextual fear memory, and pattern separation. The impaired learning and memory of the Ezh 2 knockout mice could be attributed to the decreased proliferation of the progenitor cells. Interestingly, Ezh2 affected only reversal learning and memory, which indicates that Ezh2 may be correlated with a complex cognition that requires an active form of forgetting a prior memory. These results might provide hints about the learning and memory disabilities of individuals with neurological diseases. Our data provide the first evidence for a behavioral function of Ezh2 in the adult brain. In the larger scheme, it will be important to screen for drugs that can manipulate Ezh2 activity 
to treat neurological disorders related to learning and memory defects.

\section{References}

Alvarez-Buylla A, Lim DA (2004) For the long run: maintaining germinal niches in the adult brain. Neuron 41:683-686. CrossRef Medline

Amiri A, Cho W, Zhou J, Birnbaum SG, Sinton CM, McKay RM, Parada LF (2012) Pten deletion in adult hippocampal neural stem/progenitor cells causes cellular abnormalities and alters neurogenesis. J Neurosci 32: 5880-5890. CrossRef Medline

Battiste J, Helms AW, Kim EJ, Savage TK, Lagace DC, Mandyam CD, Eisch AJ, Miyoshi G, Johnson JE (2007) Ascll defines sequentially generated lineage-restricted neuronal and oligodendrocyte precursor cells in the spinal cord. Development 134:285-293. CrossRef Medline

Bonaguidi MA, Wheeler MA, Shapiro JS, Stadel RP, Sun GJ, Ming GL, Song H (2011) In vivo clonal analysis reveals self-renewing and multipotent adult neural stem cell characteristics. Cell 145:1142-1155. CrossRef Medline

Cetin A, Komai S, Eliava M, Seeburg PH, Osten P (2006) Stereotaxic gene delivery in the rodent brain. Nat Protoc 1:3166-3173. Medline

Clelland CD, Choi M, Romberg C, Clemenson GD Jr, Fragniere A, Tyers P, Jessberger S, Saksida LM, Barker RA, Gage FH, Bussey TJ (2009) A functional role for adult hippocampal neurogenesis in spatial pattern separation. Science 325:210-213. CrossRef Medline

Cohen MM Jr (2003) Mental deficiency, alterations in performance, and CNS abnormalities in overgrowth syndromes. Am J Med Genet C Semin Med Genet 117C:49-56. CrossRef Medline

Fasano CA, Dimos JT, Ivanova NB, Lowry N, Lemischka IR, Temple S (2007) shRNA knockdown of Bmi-1 reveals a critical role for $\mathrm{p} 21-\mathrm{Rb}$ pathway in NSC self-renewal during development. Cell Stem Cell 1:87-99. CrossRef Medline

Feng W, Khan MA, Bellvis P, Zhu Z, Bernhardt O, Herold-Mende C, Liu HK (2013) The chromatin remodeler CHD7 regulates adult neurogenesis via activation of SoxC transcription factors. Cell Stem Cell 13:62-72. CrossRef Medline

Gheusi G, Cremer H, McLean H, Chazal G, Vincent JD, Lledo PM (2000) Importance of newly generated neurons in the adult olfactory bulb for odor discrimination. Proc Natl Acad Sci U S A 97:1823-1828. CrossRef Medline

Gibson WT, Hood RL, Zhan SH, Bulman DE, Fejes AP, Moore R, Mungall AJ, Eydoux P, Babul-Hirji R, An J, Marra MA, Chitayat D, Boycott KM, Weaver DD, Jones SJ (2012) Mutations in EZH2 cause Weaver syndrome. Am J Hum Genet 90:110-118. CrossRef Medline

Graves LA, Heller EA, Pack AI, Abel T (2003) Sleep deprivation selectively impairs memory consolidation for contextual fear conditioning. Learn Mem 10:168-176. CrossRef Medline

Gregorian C, Nakashima J, Le Belle J, Ohab J, Kim R, Liu A, Smith KB, Groszer M, Garcia AD, Sofroniew MV, Carmichael ST, Kornblum HI, Liu $\mathrm{X}, \mathrm{Wu} \mathrm{H}$ (2009) Pten deletion in adult neural stem/progenitor cells enhances constitutive neurogenesis. J Neurosci 29:1874-1886. CrossRef Medline

Guo W, Allan AM, Zong R, Zhang L, Johnson EB, Schaller EG, Murthy AC, Goggin SL, Eisch AJ, Oostra BA, Nelson DL, Jin P, Zhao X (2011) Ablation of Fmrp in adult neural stem cells disrupts hippocampus-dependent learning. Nat Med 17:559-565. CrossRef Medline

Guo W, Patzlaff NE, Jobe EM, Zhao X (2012) Isolation of multipotent neural stem or progenitor cells from both the dentate gyrus and subventricular zone of a single adult mouse. Nat Protoc 7:2005-2012. CrossRef Medline

Kausch I, Lingnau A, Endl E, Sellmann K, Deinert I, Ratliff TL, Jocham D, Sczakiel G, Gerdes J, Böhle A (2003) Antisense treatment against Ki-67 mRNA inhibits proliferation and tumor growth in vitro and in vivo. Int $J$ Cancer 105:710-716. CrossRef Medline

Kohman RA, Bhattacharya TK, Kilby C, Bucko P, Rhodes JS (2013) Effects of minocycline on spatial learning, hippocampal neurogenesis and microglia in aged and adult mice. Behav Brain Res 242:17-24. CrossRef Medline

Lagace DC, Whitman MC, Noonan MA, Ables JL, DeCarolis NA, Arguello AA, Donovan MH, Fischer SJ, Farnbauch LA, Beech RD, DiLeone RJ, Greer CA, Mandyam CD, Eisch AJ (2007) Dynamic contribution of nestin-expressing stem cells to adult neurogenesis. J Neurosci 27:1262312629. CrossRef Medline

Lie DC, Colamarino SA, Song HJ, Désiré L, Mira H, Consiglio A, Lein ES,
Jessberger S, Lansford H, Dearie AR, Gage FH (2005) Wnt signalling regulates adult hippocampal neurogenesis. Nature 437:1370-1375. CrossRef Medline

Lim DA, Huang YC, Swigut T, Mirick AL, Garcia-Verdugo JM, Wysocka J, Ernst P, Alvarez-Buylla A (2009) Chromatin remodelling factor Mll1 is essential for neurogenesis from postnatal neural stem cells. Nature 458: 529-533. CrossRef Medline

Liu C, Teng ZQ, Santistevan NJ, Szulwach KE, Guo W, Jin P, Zhao X (2010) Epigenetic regulation of miR-184 by MBD1 governs neural stem cell proliferation and differentiation. Cell Stem Cell 6:433-444. CrossRef Medline

Lugert S, Basak O, Knuckles P, Haussler U, Fabel K, Götz M, Haas CA, Kempermann G, Taylor V, Giachino C (2010) Quiescent and active hippocampal neural stem cells with distinct morphologies respond selectively to physiological and pathological stimuli and aging. Cell Stem Cell 6:445-456. CrossRef Medline

Ma DK, Marchetto MC, Guo JU, Ming GL, Gage FH, Song H (2010) Epigenetic choreographers of neurogenesis in the adult mammalian brain. Nat Neurosci 13:1338-1344. CrossRef Medline

Mangi AA, Noiseux N, Kong D, He H, Rezvani M, Ingwall JS, Dzau VJ (2003) Mesenchymal stem cells modified with Akt prevent remodeling and restore performance of infarcted hearts. Nat Med 9:1195-1201. CrossRef Medline

Margueron R, Justin N, Ohno K, Sharpe ML, Son J, Drury WJ 3rd, Voigt P, Martin SR, Taylor WR, De Marco V, Pirrotta V, Reinberg D, Gamblin SJ (2009) Role of the polycomb protein EED in the propagation of repressive histone marks. Nature 461:762-767. CrossRef Medline

Mira H, Andreu Z, Suh H, Lie DC, Jessberger S, Consiglio A, San Emeterio J, Hortigüela R, Marqués-Torrejón MA, Nakashima K, Colak D, Götz M, Fariñas I, Gage FH (2010) Signaling through BMPR-IA regulates quiescence and long-term activity of neural stem cells in the adult hippocampus. Cell Stem Cell 7:78-89. CrossRef Medline

Molofsky AV, Pardal R, Iwashita T, Park IK, Clarke MF, Morrison SJ (2003) Bmi-1 dependence distinguishes neural stem cell self-renewal from progenitor proliferation. Nature 425:962-967. CrossRef Medline

O'Carroll D, Erhardt S, Pagani M, Barton SC, Surani MA, Jenuwein T (2001) The polycomb-group gene Ezh2 is required for early mouse development. Mol Cell Biol 21:4330-4336. CrossRef Medline

Pan YW, Chan GC, Kuo CT, Storm DR, Xia Z (2012) Inhibition of adult neurogenesis by inducible and targeted deletion of ERK5 mitogenactivated protein kinase specifically in adult neurogenic regions impairs contextual fear extinction and remote fear memory. J Neurosci 32:64446455. CrossRef Medline

Pereira JD, Sansom SN, Smith J, Dobenecker MW, Tarakhovsky A, Livesey FJ (2010) Ezh2, the histone methyltransferase of PRC2, regulates the balance between self-renewal and differentiation in the cerebral cortex. Proc Natl Acad Sci U S A 107:15957-15962. CrossRef Medline

Pollak DD, Monje FJ, Lubec G (2010) The learned safety paradigm as a mouse model for neuropsychiatric research. Nat Protoc 5:954-962. CrossRef Medline

Pun RY, Rolle IJ, Lasarge CL, Hosford BE, Rosen JM, Uhl JD, Schmeltzer SN, Faulkner C, Bronson SL, Murphy BL, Richards DA, Holland KD, Danzer SC (2012) Excessive activation of mTOR in postnatally generated granule cells is sufficient to cause epilepsy. Neuron 75:1022-1034. CrossRef Medline

Saxe MD, Battaglia F, Wang JW, Malleret G, David DJ, Monckton JE, Garcia AD, Sofroniew MV, Kandel ER, Santarelli L, Hen R, Drew MR (2006) Ablation of hippocampal neurogenesis impairs contextual fear conditioning and synaptic plasticity in the dentate gyrus. Proc Natl Acad Sci U S A 103:17501-17506. CrossRef Medline

Sebastian V, Diallo A, Ling DS, Serrano PA (2013) Robust training attenuates TBI-induced deficits in reference and working memory on the radial 8-arm maze. Front Behav Neurosci 7:38. CrossRef Medline

Shen X, Liu Y, Hsu YJ, Fujiwara Y, Kim J, Mao X, Yuan GC, Orkin SH (2008) EZH1 mediates methylation on histone $\mathrm{H} 3$ lysine 27 and complements EZH2 in maintaining stem cell identity and executing pluripotency. Mol Cell 32:491-502. CrossRef Medline

Sher F, Rössler R, Brouwer N, Balasubramaniyan V, Boddeke E, Copray S (2008) Differentiation of neural stem cells into oligodendrocytes: involvement of the polycomb group protein Ezh2. Stem Cells 26:28752883. CrossRef Medline

Smrt RD, Eaves-Egenes J, Barkho BZ, Santistevan NJ, Zhao C, Aimone JB, 
Gage FH, Zhao X (2007) Mecp2 deficiency leads to delayed maturation and altered gene expression in hippocampal neurons. Neurobiol Dis 27: 77-89. CrossRef Medline

Soares LM, Schiavon AP, Milani H, de Oliveira RM (2013) Cognitive impairment and persistent anxiety-related responses following bilateral common carotid artery occlusion in mice. Behav Brain Res 249:28-37. CrossRef Medline

Stambolic V, Suzuki A, de la Pompa JL, Brothers GM, Mirtsos C, Sasaki T, Ruland J, Penninger JM, Siderovski DP, Mak TW (1998) Negative regulation of PKB/Akt-dependent cell survival by the tumor suppressor PTEN. Cell 95:29-39. CrossRef Medline

Stiles CD (2003) Lost in space: misregulated positional cues create tripotent neural progenitors in cell culture. Neuron 40:447-449. CrossRef Medline

Suh H, Consiglio A, Ray J, Sawai T, D’Amour KA, Gage FH (2007) In vivo fate analysis reveals the multipotent and self-renewal capacities of Sox $2+$ neural stem cells in the adult hippocampus. Cell Stem Cell 1:515-528. CrossRef Medline

Tatton-Brown K, Hanks S, Ruark E, Zachariou A, Duarte Sdel V, Ramsay E, Snape K, Murray A, Perdeaux ER, Seal S, Loveday C, Banka S, Clericuzio C, Flinter F, Magee A, McConnell V, Patton M, Raith W, Rankin J, Splitt M, et al. (2011) Germline mutations in the oncogene EZH2 cause Weaver syndrome and increased human height. Oncotarget 2:1127-1133. Medline

Tetsu O, McCormick F (1999) Beta-catenin regulates expression of cyclin D1 in colon carcinoma cells. Nature 398:422-426. CrossRef Medline

van Praag H, Schinder AF, Christie BR, Toni N, Palmer TD, Gage FH (2002) Functional neurogenesis in the adult hippocampus. Nature 415:10301034. CrossRef Medline

Vorhees CV, Williams MT (2006) Morris water maze: procedures for assessing spatial and related forms of learning and memory. Nat Protoc 1:848-858. CrossRef Medline
Winocur G, Wojtowicz JM, Sekeres M, Snyder JS, Wang S (2006) Inhibition of neurogenesis interferes with hippocampus-dependent memory function. Hippocampus 16:296-304. CrossRef Medline

Yilmaz OH, Valdez R, Theisen BK, Guo W, Ferguson DO, Wu H, Morrison SJ (2006) Pten dependence distinguishes haematopoietic stem cells from leukaemia-initiating cells. Nature 441:475-482. CrossRef Medline

Yoshimi A, Goyama S, Watanabe-Okochi N, Yoshiki Y, Nannya Y, Nitta E, Arai S, Sato T, Shimabe M, Nakagawa M, Imai Y, Kitamura T, Kurokawa M (2011) Evil represses PTEN expression and activates PI3K/AKT/ mTOR via interactions with polycomb proteins. Blood 117:3617-3628. CrossRef Medline

Zhang CL, Zou Y, He W, Gage FH, Evans RM (2008a) A role for adult TLX-positive neural stem cells in learning and behaviour. Nature 451: 1004-1007. CrossRef Medline

Zhang M, Moon C, Chan GC, Yang L, Zheng F, Conti AC, Muglia L, Muglia LJ, Storm DR, Wang H (2008b) Ca-stimulated type 8 adenylyl cyclase is required for rapid acquisition of novel spatial information and for working/episodic-like memory. J Neurosci 28:4736-4744. CrossRef Medline

Zhao C, Teng EM, Summers RG Jr, Ming GL, Gage FH (2006) Distinct morphological stages of dentate granule neuron maturation in the adult mouse hippocampus. J Neurosci 26:3-11. CrossRef Medline

Zhao C, Deng W, Gage FH (2008) Mechanisms and functional implications of adult neurogenesis. Cell 132:645-660. CrossRef Medline

Zhao X, Ueba T, Christie BR, Barkho B, McConnell MJ, Nakashima K, Lein ES, Eadie BD, Willhoite AR, Muotri AR, Summers RG, Chun J, Lee KF, Gage FH (2003) Mice lacking methyl-CpG binding protein 1 have deficits in adult neurogenesis and hippocampal function. Proc Natl Acad Sci U S A 100:6777-6782. CrossRef Medline 